Portland State University

PDXScholar

\title{
The role of iron nutrition in regulating patterns of photosynthesis and nitrogen metabolism in the green alga Scenedesmus quadricauda
}

Dennis Raymond Ades

Portland State University

Follow this and additional works at: https://pdxscholar.library.pdx.edu/open_access_etds

Part of the Biology Commons, and the Plant Sciences Commons

Let us know how access to this document benefits you.

\section{Recommended Citation}

Ades, Dennis Raymond, "The role of iron nutrition in regulating patterns of photosynthesis and nitrogen metabolism in the green alga Scenedesmus quadricauda" (1987). Dissertations and Theses. Paper 3649. https://doi.org/10.15760/etd.5533

This Thesis is brought to you for free and open access. It has been accepted for inclusion in Dissertations and Theses by an authorized administrator of PDXScholar. Please contact us if we can make this document more accessible: pdxscholar@pdx.edu. 
AN AESTFACT of THE THESIS OF Dennis Raymond Ades for the Master of Science in Eiology presented September 19, 1986.

Title: The Fole of Iron Nutrition in Fiegulating Fatterns of Fhotosynthesis and Nitrogen Metabolism in the Green Alga

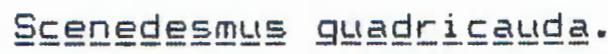

AFFFIUED EY MEMEEFS DF THE THESIS COMMITTEE:

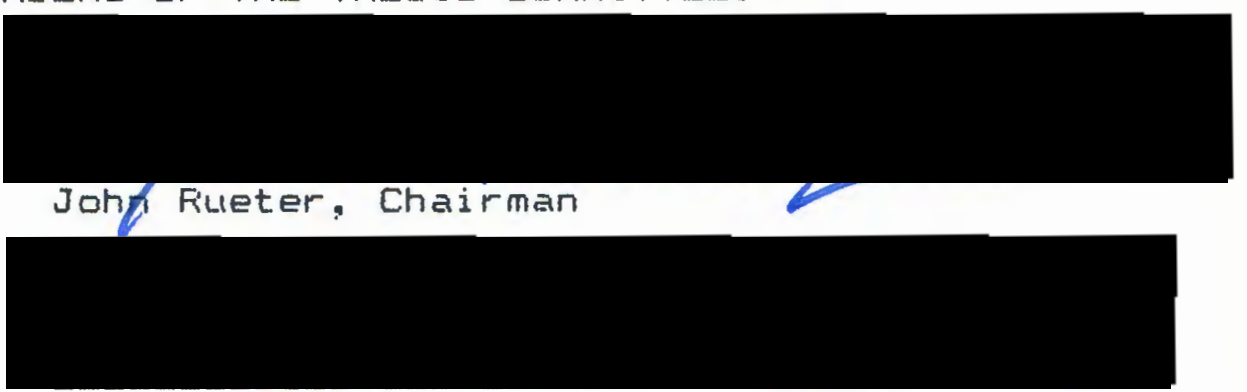

Fichard Fetersen

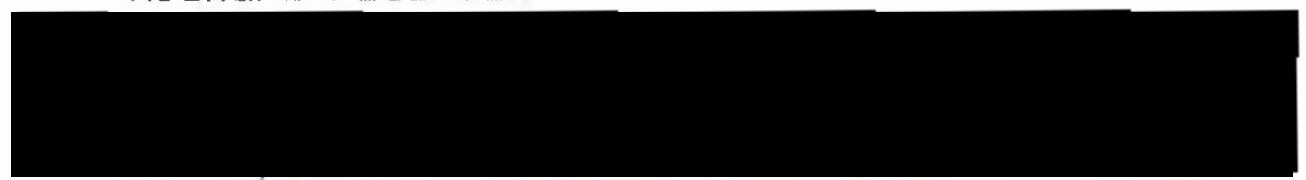

Fichard Tocher

The influence of iron nutrition on patterns of photosynthetic behavior, nitrogen metabolism, and fixedcarbon allocation is reported for a common freshwater green

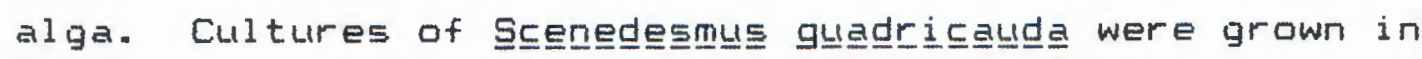
Fraquil medium in which iron concentrations ranged from 1.0 4M to $0.01 \mu M$ ( Iog 10-6 to 10-g M, respectively). Carbon 14 and nitrugen uptake experiments were conducted at 
photosynthetically saturating and sutsaturating photon flux densities.

S= g느르모드르느므 responded to iron deficiency with reductions in chlorophyll a concentrations, cellular fluorescence characteristics, and 14C uptake. Froton flux density strongly affected the rate of carbon fixation and photosynthetically saturating light intensity compensated for moderate iron deficiencies. Cellular fluorescence capacity: a measure of 1 ight-saturated photosynthetic capacity relative to the photochemical capacity of an algal culture, was linted to photosyritietic rates and efficiencies.

Fieductions in iron concentrations and irradiarice were found to decrease protosynthesis sufficiently to energetically hirider the utilization of nitrate in the culture medium. However, depletion of ammonium from the culture medium was largely independent of iron nutrition and irradiance. Ammonium uptatie rates exceeded nitrate uptake rates in all iron and light regimes.

Chloroptyll a concentrations and carbon-fixation rates in nitrogen-sufficient and nitrogen-deficient cul tures were strongly influenced by the iron concentration of the medium. Nitrogen nutrition appeared to affect chloroptiyll a concentrations only in iron-replete cultures. Cultures enriched with nitrate supported less photoassimilation of 
14C than ammonium-nourished cultures. This is lit:ely due to the greater amourit of photochemical energy required to fully metabolize nitrate.

Fatterns of carton incorporation into cellular components were also controlled by iron nutrition and irradiance. Much of the carbon fixed in iron-deficient cultures was allocated to protein whereas in iron-sufficient cultures, most of the $14 \mathrm{C}$ label was recovered in the polysaccharide component. This suggests that iron-stressed algal cultures maintain the synthesis of metabolic machinery such as proteins and enzymes at the expense of other cellular comporients. Iron-replete cultures fixed more inorganic carbon and possibly stored the additional fixed carbon as starch. This partitoning behavior is examined briefly with a conceptual model. 
THE FILLE OF IFION NUTFITION IN FEGULATING FATTEFNS OF FHOTOSYNTHESIS AMD NITFOGEN METAEOLISH

IN THE GFEEN ALGA SCENEDESMUS QUADEICEUDEA

\title{
by
}

DENNIS FAYMOND ADES

A thesis submitted in partial fulfillment of the
requirements for the degree of

\author{
MASTEF OF SCIENCE \\ i $\pi$ \\ EIOLDGY
}

Fortland State University

1987 
TO THE IFFILE OF GRADUATE STUDIES AND FESEAF:CH:

The members of the Committee approve the thesis of

Denmis Fiaymond Ades presented September 18, 1986.

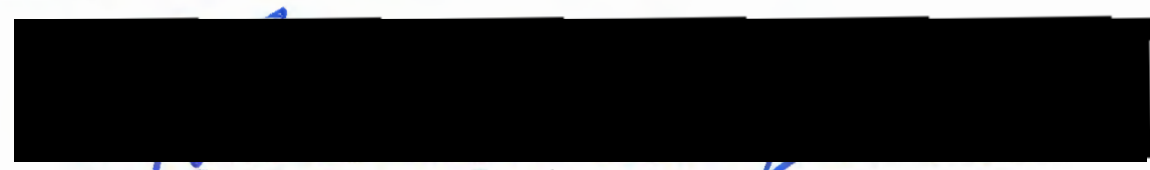

Johd G. Fueter, Chairman

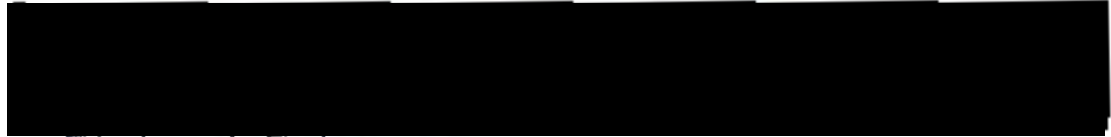

Richard Fetersen

Fichard Tocher

AFFFOVED:

Fichard Fietersen. Head, Biology Department

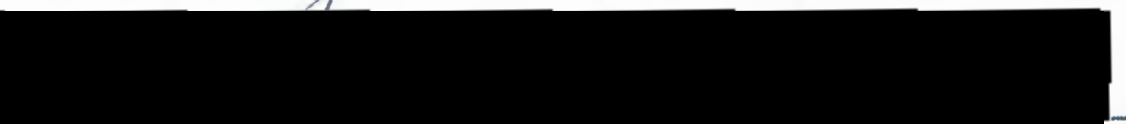

Eernard Foss, Dean of Graduate Studies and Fiesearch 


\section{ACKNOWLEDGEMENTS}

I would lit:e to thank my labo coworkers for their participation in this research effort. Their assistance in all phases of this project was invaluable. A special thant:s to John Rueter for his guidance, enthusiasm and most importantly, for lieeping the Frincess under cantrol. I am gratefully indebted to Leslie who patiently encouraged me as I struggled to complete this thesis. I should also recognize her role as proofreader and editor for the numerous drafts and papers I have prepared in the last two years. 
TAELE UF CONTENTS

FAGE

ACKNOWLEDGEMENTS. ............................. i i i

LIST OF TAELES .......................... vi

LIST DF FIGUFES......................... vi

CHAFTEF

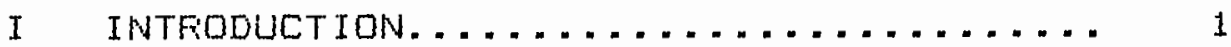

I I METHDDS........................... 10

Measurements of Fhotosynthesis...... 14

Measurements of Nitrate and Ammonium Uptake Fiates.................... 15

Fatterns of Carbon Metabolism....... 17

II I THE INFLUENCE DF IFION AVAILAEILITY

ON FHOTOSYNTHESIS IN

SEEWEDESMUS QUADEICAUDA. . . . . . ......

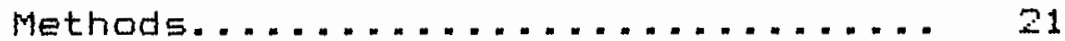

Fesults........................ 22

Cellular Fluorescence Capacity Fhotosynthetic Fiates

Di scussion........................ 2

Chlorophyll a Concentration

Cellular Fluorescence Capacity

Fhotosynthetic Rates

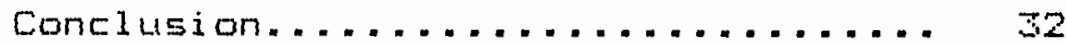


IV THE EFFECTS OF IRON DEFICIENCY ON NITFOGEN METAEOL ISM AND SOME

FHYSIOLOGICAL FESFONGES...............

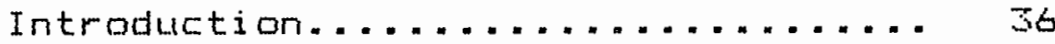

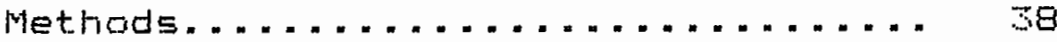

Fiesults.......................... . . . 40

Inorganic Nitrogen Uptake

Chloroptiyl $\mathrm{a}$

Fhotosynthetic Rates

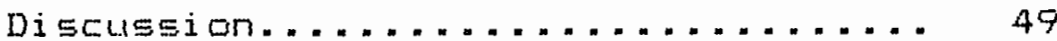

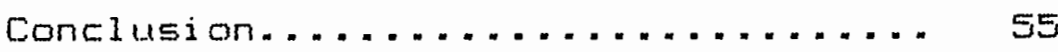

$\checkmark$ FEGLLATION OF FATTERNS IN SHOFT-TERM

CAFEON METAEOL ISM EY IRON NUTFITION..... 57

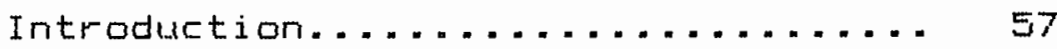

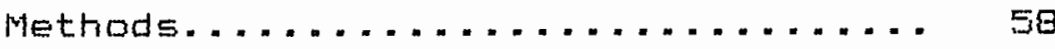

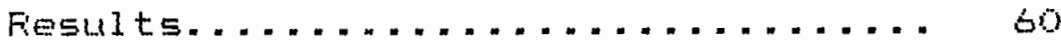

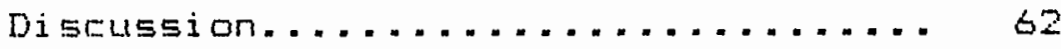

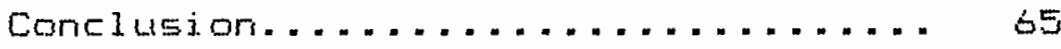

VI A GENEFIAL MODEL FOR IFON LIMITATION

AND ENVIRONMENTAL SIGNIFICANCE........

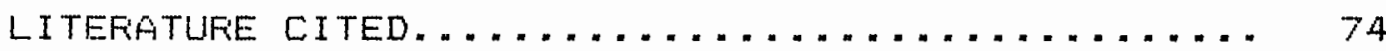




\section{LIST OF TAELES}

TAELE

PAGE

I Modified Fraquil Culture Medium...............1 


\section{LIST OF FIGURES}

FIGUFIE

FAGE

1. The Nitrate Feduction and Assimilation

Fathway..........................

2. The Sequential Extraction of 14C-

Labelled Cellular Components..........

3. Chlorophyl1 a Concentrations Increase

as a Function of Iron Concentration

in the Media.

4. Cellular Fluorescence Capacity (1-In

Yivo Fluorescence/DCHU-Induced

Fluorescence Increases with Greater

Iron Sufficiency................. 25

5. 14C Uptake per Chlorophyll a

Demonstrates a Functional Fesponse to

Iron at all Photon Flux Densities..... 27

6. 14C Uptatie per Chlorophyll a Fielative

to Fhoton Flux Density Indicates that

Carbon Assimilation or Fhotasynthetic

Efficiency is Controlled by Iron

Nutrition........................

7. Fhotosynthetic Efficiency is Linked to

Cellular Fluorescence Capacity........ 
9. Nitrate Uptalie Fates per Chlorophyll a Increase with Greater Iron Mutrition

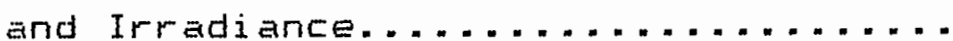

7. A Comparison of Nitrate and Ammonium

Depletion From the Culture Medium

During a 30 Minute Dart: Incubation....

10. Nitrate and Ammonium Uptake Fiates as a

Function of Irradiance or Fhoton Flux

Density.........................

11. Ch1oroptyll a Concentrations Examined

Examined as a Function of Iron and

Nitrate Nutrition Indicates that Iron

More Strorigly Contrals Chlaraptiyl 1

Concnetrations than Nitrate...........

12. The Influence of Light Intensity and Nitrate Nutrition on 14C Uptate........

13. A Comparison of the Influence of Nitrate and Ammonium-Nitrogen Sources on

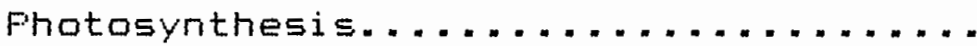

14. Fatterns of 14C Incorporation into

Cellular Components Indicate that Greater than $50 \%$ of the Fhotoassimilated Carbon is Allocated to the Frotein Component in Iron-Deficient Cultures... 
15. A Comparison of Fhotosynthetic Fates and $14 C$ Incorporation into Frotein Reveals that Frotein Accounts for a Fielatively Constant Fercentage of Incorporated $14 \mathrm{C}$ in Cultures with Moderate to High Iron Nutrition.......... s... 1.5. The Effects of Iron Supply on Cellular Composition Demonstrated with the Stiuter Model Approach................ 


\section{CHAFTEF I}

\section{INTRODUCT ION}

Fhotosynthesis and algal growth rates in natural waters are determined by a myriad of biological, chemical, and physical factors. Typically, sunlight and macronutrients such as ritrogen and phosphorus are thought to be the primary growth-limiting parameters in aquatic ecosystems. However with advances in trace metal culturing techniques, the important role iron and other trace metals play in controlling primary productivity is becaming more apparent.

As cofactors in metalloerizymes and electron transfer proteins, trace metals are essential for the most basic metabolic processes. Iron, for example, accurs in such fundamental metabolic pathways as photosynthesis, respiration, and nitrogen metabolism. The large difference in redox potential of ferraus (Fet?) and ferric (Fet mates iron an ideal electron carrier. However, this basic biological requirement for iron and other trace metals is frequently complicated by their relatively low coricentrations in natural waters. With this in mind, it is not suprising to fird that iron-deficiencies do develop in 
freshwater and marine ecosystems which can limit primary productivity Goldman, 1972; Miller et al., 1974; Glover, 1977 and $1978 ;$ and Eirand et al., 1983).

Iron concentrations in oxygenated waters are usually very low because the relatively soluble ferrous iron undergoes rapid oxidation to ferric iron. Ferric iron rapidly precipitates from the water column or binds with hydroxides and orthophosphate rendering it unavailatue for algal use. In organic-rich waters, ferric iron forms stable colloids and organic complexes which increases the total iron concentration in the water column (Wetzel, 1975). Fhotodegradation of these complexes may produce transient ferrous iron concentrations which can be rapidly assimilated by algae (Colliene, 198S).

The rate of iron axidation and coiloid formation is strongly dependert on $\mathrm{pH}$. In reducing environments such as the anoxic hypalimnion of a eutrophic late, ferric iron in the sediments is reduced to ferrous iron and diffuses upward into the water column. This process, however, is gerierally restricted to anoxic environments and is not an important factor in controlling iron availability in the less productive surface waters of an oligotrophic late or ocean.

Iron uptat:e processes in elliaryotic algae are poorly understood because of the complicated aquatic chemistry of iron. Anderson and Morel (1982) identified a membrane-bound 
transfer molecule which mediated iron uptatie in the marine

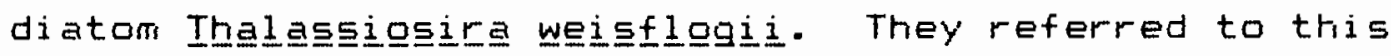
transport molecule as "phytotransferrin" because of its behavioral similarity to the transferrin molecule in

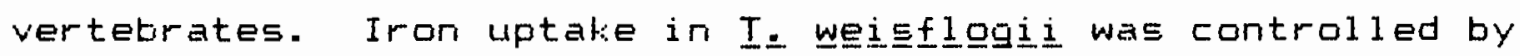
the free ion activity hypothesized to relate to the saturation of the phytotransferrin molecule and was not directly lintied to photosynthesis or respiration. The biological availability of iron was therefore determined by the free ion activity of ferrous and ferric iron within the system, or the transient ians produced by the photodegradation of complexed ferric iron.

Some algae have evolved specialized strategies for growing in low-iron environments. The most successful of these are the bluemgreen algae capable of producing siderophores, low molecular weight molecules which have high affinities for iron. Iron-stressed axenic cultures of a marine dinoflagellate have also been reported to produce a siderophore-lite substance, although in much lower concentrations than cyanophytes (Trict et a1., 1983). Siderophores facilitate iron uptake by dissolving iron oxides and mating ferric iron available to the algal population producing the siderophores. The entire siderophore-iron complex is either transported across the cell membrane or the iron is reduced and taken up separately (Lewin, 1984 ). 
Siderophores are species specific and sequester iron from the remairider of the algal community. This confers a competitive advantage to siderophore producing algae during periods of low iron availability. In S드므르틈능 for example, growth is reduced by $80 \%$ and coenobia are disrupted and become chlorotic when grown in the presence of a siderophore extracted from cultures of Anghäeng Murphy et al., 1970). However, sensitivity to siderophores differs

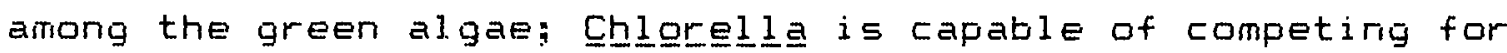
sideraphare-chelated iron much more successfully than

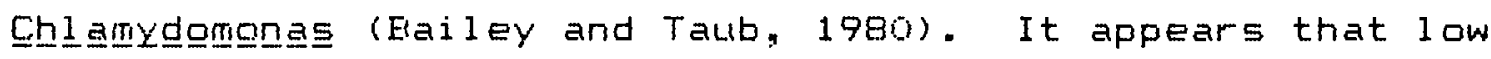
iron concentrations may not only influence the level of productivity in an aquatic ecosystem, but because of the ability of same algae to produce siderophores, iror availability may strongly determine the species composition and diversity of the algal community within that ecosystem.

Two types of physiological responses to irondeficiency may be seen in algae. Iron starvation may interfere with the biasynthesis of polymers and cellular components in a manner similar to other nutrient deficiencies, or decrease rates of inorganic carbon assimilation in a behavioral response usually seen in lightI imited cultures.

Concentrations of chlorophyll a and other phatasynthetic pigments and proteins are lower in iron-stressed 
algal populations than they are in iron-sufficient algae COquist, 1971; Glover, 1977; Verstreate et a1., 1980; and Sandmann and Malkin, 1985; Mueller, 1985). Iron, in the form of the photosynthetic iron-sulfur protein ferredoxin. plays an important role in activating the synthesis of heme group precursors to chlorophyll and cytachromes. The reduction in photosynthetic pigments and cytachromes results in decreased light-harvesting capacity and photosynthetic electron flow during phatosyrthesis (Sandmann and Malkin: 1985

Iron enrichment has beer shown to stimulate inorganic carbon-fixation in freshwater algae, although ptiotosynthesis may be inhibited with higher concentrations (3.6 to $17.9 \mathrm{fM}$ ) of chelated and unctielated irori (Storch and Duriham, 1986). Fhotosynthetic rates and carbon assimilation numbers are al $\leqq$ lower in iron-deficient cultures of marine algae (Glover, 1977). Simultaneous reductions in light harvesting capacity and photosynthetic rates suggest that growth rates in low-iron cultures may be at least partly controlled by the conversion of 1 ight energy into chemical energy.

Iron nutrition also controls patterns of inorganic nitrogen metabolism in algae, contributing to each step of nitrate reduction and assimilation. Iron occurs in the nitrate reductase and nitrite reductase enzymes and in ferredaxin, which regulates the flow of photoreductant to 
the nitrogen metabolism pathway. A generalized illustration of nitrate reduction and assimilation is shown in figure 1.

Iron nutrition has been suggested to regulate patterns of nitrogen fination activity in blue-green algae by controlling the synthesis of glutamine synthetase (Verstreate et al., 1980). Glutamine synthetase apparently inhibits the activity of nitrogenase, the enzyme responsible for reduction of atmaspheric nitragen. When iron-nutritian is sufficient and nitrate concentrations are low, glutamine synthetase is not synthesized and nitrogen-fixation tates place. Elue-green algae may be energetically stressed if iron supply is low. In this condition glutamine synthetase is synthesized and the metabolically experisive process of nitrogen fixation is inhibited.

The role of iron in controlling nitrogen metabalism in green algae has not been well studied. In a study with

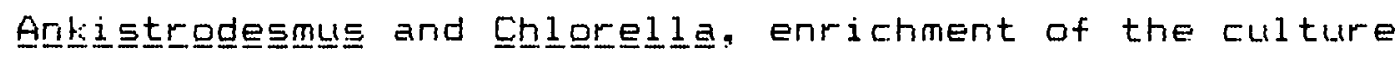
medium with EDTA-chelated iron specifically increased the reduction of nitrite without affecting the reduction of nitrate to nitrite (Kiessler and Caygan, 1967). It is not clear whether iron is required for the synthesis of the enzyme nitrite reductase or to insure an adequate supply of reductant. More recently: Verstreate et al. (1980) found that iron concentrations greater than 0.2 M Fet2 inhibited nitrate reductase and glutamine synthetase activity in 


\section{PHOTOSYNTHESIS}

$\downarrow$

reducing

Power

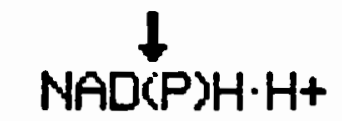

carbohydrates

RESPIRATION

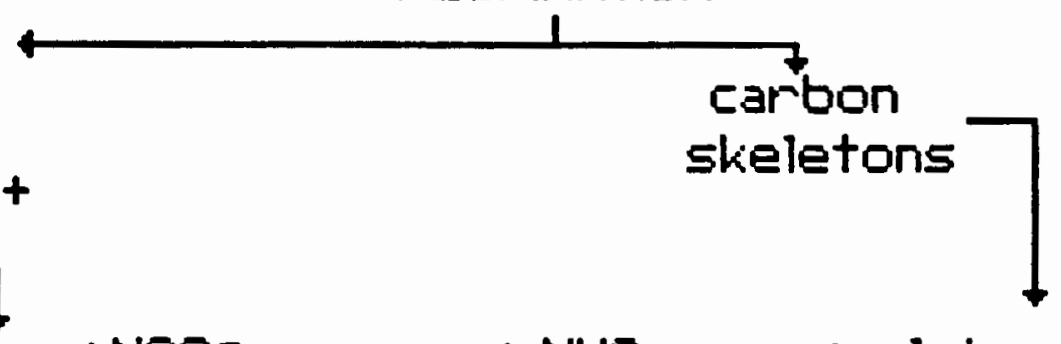

$\mathrm{NO3}^{-} \stackrel{+}{\longrightarrow} \mathrm{NO2}$

NRase

NiRase

$\rightarrow \mathrm{Fd}$

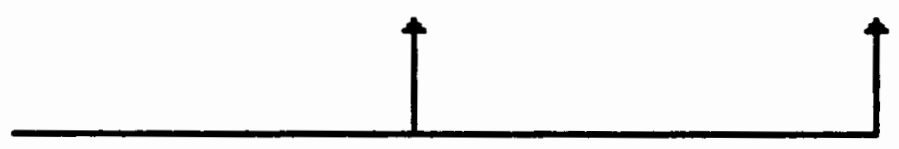

glutamate

$\mathrm{NH3}$

GS/GOGAT

\section{$+$ \\ NITRIIGENIUUS \\ CELLULAR COMPONENTS}

Figure 1. The nitrate reduction and assimilation pathway. Reductant generated in photosynthesis and respiration flows through nicotinamide adenine dinucleotide phosphate (NADFH $H+$ ) and ferredoxin (Fd) to enzymes in the nitrate reduction pathway. NFiase-nitrate reductase; Nifiase-nitrite reductase; GS/GOGAT- glutamine synthetase/glutamate synthetase. Not shown is the involvement of ATF in the active transport of nitrate and glutamine synthetase/ glutamate synthetase activity. 
Scennedesmus. The cause for such intibition was not identified or speculated although lower concentrations of these enzymes were al so observed in cul tures with greater iron concentrations.

The relative abundance of cellular comporients such as proteins, lipids, and polysaccharides may reflect the nutritional and physiological status of an algal culture. Fatterns of inorganic carbon metabolism, like nitrogen, are also affected by iron nutrition. Glover (1977) reported a greater proportion of fixed $14 \mathrm{C}$ was found in protein in iron-deficient cultures than in iron-sufficient cultures. This pattern of carton metabolism is similar to that observed in energetically-limited cultures grown at lowlight intensities (Morris et al., 1974).

Iron nutrition can control the synthesis of photosynthetic pigments and proteins, patterns of photosynthesis, nitrogen metabolism, and carbon assimilation. This effort has focused on identifying these patterns in the green alga,

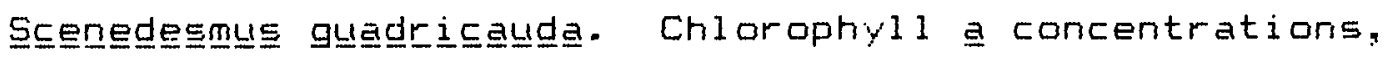
fluorescence response, and carbon-fixation rates will be examined as a function of the iron concentration in the culture medium and light intensity in chapter III. This will provide information on the energetic and nutrient interactions of iron-deficiency. Energetic interactions are further examined as they pertain to nitrogen metabolism in 
Chapter IV. Nitrogen uptalie and assimilation is an energetical1y costly yet basic metabolic process in algae. To further elucidate the overall physiological response to iron-nutrition chapter $V$ will discuss stiort-term patterns in carbon metabolism at various levels of iron nutrition and irradiance. This information will be compiled and viewed from an environmental perspective in chapter VI. 
CHAF'TEF I I

METHODS

Semi-continuaus batch cultures of the chlorophyte

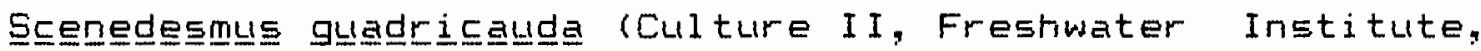
Winnipeg, Canada) were grown in complete Fraquil medium (Morel et al., 1979; as modified by Fetersen, 1982; Table 1) and used as maintenance stock: for experimental cultures. Cultures were incubated at $22^{\circ} \mathrm{C}$ with continuous cool-white 1 ight at $100 \mathrm{\mu Ej}$ (nsteins/ma/sec in $500 \mathrm{ml}$ erlermeyer flast:s. Culture flast:s were swirled daily to facilitate gas exchange and to keep cells in suspension.

Fraquil medium was prepared with concentrated rutrierit stock: solutions which were added to Naropure reagent-grade water (Sybron/Earnstead; 916.7 megaohms). The medium was Passed through a cation exchange column Cheles 100, Eio-rad Laboratories) to remove trace metal contaminants before metals were added. The complete medium was filter sterilized (gravity or vaculm-filtered at less than 5 psi) through acid leactied $0.2 \mu m$ Nucleopore filters and $\mathrm{pH}$ adjusted to $7.5 \pm 0.1$. All glassware and plasticware were soaked $24 \mathrm{hr}$ in $5 \% \mathrm{HCl}$ and rinsed in Nanopure water to minimize contamination. 
TAELE I

MODIFIED FFAOUIL CULTUFE MEDIUM

\begin{tabular}{|c|c|c|c|}
\hline $\begin{array}{l}\text { chemical } \\
\text { component }\end{array}$ & $\begin{array}{c}\text { concentration } \\
\text { mol } / L\end{array}$ & $\begin{array}{l}\text { chemical } \\
\text { component }\end{array}$ & $\begin{array}{c}\text { concentration } \\
\text { mol } / L\end{array}$ \\
\hline $\mathrm{Ca}+2$ & $2.5 \times 10-4$ & $c 03-2$ & $1.5 \times 10-4$ \\
\hline $\mathrm{Mg}+2$ & $1.5 \times 10-4$ & $504-$ & $1.5 \times 10-4$ \\
\hline ケ+ & $2.0 \times 10-5$ & $\mathrm{Cl}-$ & $5.2 \times 10-4$ \\
\hline$F E+S$ & $1.0 \div 10-6$ & $\mathrm{E}(\mathrm{OH}) 3$ & $1.0 \times 10-7$ \\
\hline$M n_{1}+2$ & $1.38 \times 10-6$ & $\mathrm{MOO} 4-2$ & $1.5 \times 10-9$ \\
\hline $\mathrm{Co}+2$ & $1.25 \times 10-7$ & NoS- & $1.0 \times 10-4$ \\
\hline $2 n+2$ & $1.2 \times 10-7$ & EDTA-4 & $1.0 \times 10-6$ \\
\hline NHS & $1.5 \times 10-9$ & $A 1+3$ & $3.98 \times 10-9$ \\
\hline $\mathrm{H}+$ & $3.0 \times 10-8$ & $\mathrm{Cu}+2$ & $0.0 \times 10-8$ \\
\hline
\end{tabular}




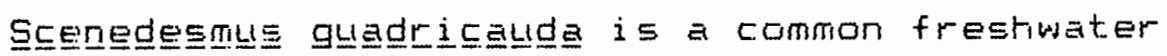
chlorcphyte frequently used in laboratory experiments.

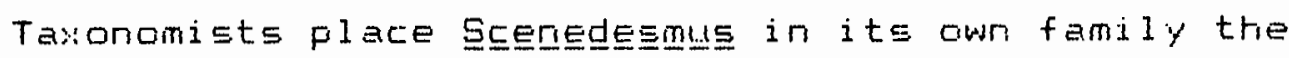
Scenedesmaceae, of the order chlorocaccales ifrescott,

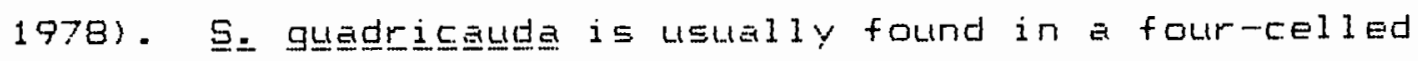
coenobium although single cells are frequently observed in natural and cultured populations.

Experimerital cultures were started by transferring aliquats of log-phase cells from 7 to 10 day old maintenance cultures to fresh iron-deficient. Fraquil medium. Iron concentrations of $1.0,0.5,0.1,0.05$, and $0.01 \mathrm{~lm} 1109$ values of $-6,-6.5,-7,-7.5$, and $-9 M$, respectively' were botained by adding appropriate valumes of 10-4M FeEDTA stock into the medium. Frior to transfer, the algal aliquats were centifuged 5 minutes at $1000 \mathrm{rpm}$, decanted, rinsed in Nanopure, and centrifuged again to minimize the transfer of exogenous nutrients. Experimentad. cul tures were al so frequently transferred to fresh medium in this manner to minimize the depletion of nutriente. Cell densities in stock and experimental cultures were manitored with a Coulter Counter electronic particle counter imodel 2907 ZEI). One $m l$ of culture was Euspended in $9 \mathrm{ml}$ of Isoton electrolyte solution and aspirated through a $100 \mathrm{\mu m}$ orifice. Ease channel threshold was adjusted to produce blant: counts less than 100. Coulter Counter results were 
occasionally verified with batch counting chamber results (Fuchs Fosenthal ultra plane counting chamber and Zeiss microscope).

Cellular fluorescence capacity (CFC: Vincent, 1980) was measured periodically in stoct: and experimental cul tures. In yivg fluorescence was measured on $5 \mathrm{ml}$ samples with a Turner Desigris model 10 fluorometer calibrated to chlorophyl1 a. 3-(3,4-dichloropheny1)-1,1dimethylurea (DCMU)-induced fluorescence was determined by adding $100 \mu$ fl of a saturated DCMU solution to the samples and remeasuring fluorescence. This provided information on the light-saturated photosynthetic capacity ard photochemical capacity of each culture. Cellular fluorescence capacity, as a measure of photosystem efficiency, may be expressed with the following equation:

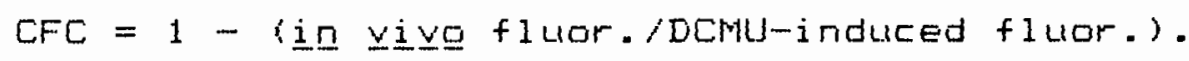

Specifications of the Turner Designs model 10 fluor ameter include:

$$
\begin{aligned}
& \text { light source-tulb FATS } \\
& \text { excitation filter-c/s } 5-60 \\
& \text { emission filter-c/s 2-64 }
\end{aligned}
$$

\section{EXFERIMENTATION}

Experiments examining photosynthesis and nitrogen uptat:e were initiated when cultures grown in different iron 
concentrations approached steady state and CFC Vallies reflected the iron-nutritional status of the cultures. This uslally occurred after 7 to 10 days of growth. CFC has been demoristrated to be very serisitive to nitrogen deficiency so it is important not to deplete nitrate concentrations in order to observe responses to iron nutrition.

MeEgurements of ehotosyrithesis. Fhotosynthetic characteristics as a function of iron nutrition were determined by the photoassimilation of $14 \mathrm{C}$. Frior to addition of Natld4Co:, chlorophyll a samples were collected by filtration onto GF/A filters and preserved with 2 to 3 drops of MgC12. The chloroptiyll samples were stored frozen in darkness until extraction. Chlorophyll a concentrations were determined using the acetone extraction techrique of Farsoris et al. (1984) in whict cells and filter are ground with a mortar and pestel, al lowed to extract overnight in $90 \%$ acetore, and analyaed fluorometrically with the Turner Designe Model 10 fluorometer calibrated for chlorophyll 르.

After time zero chlorophyll a samples were collected, cultures were equally divided in $250 \mathrm{ml}$ erlenmeyer flasks and $50 \mu l \mathrm{NaH} 14 \mathrm{CO}$, with an activity of $5.0 \mu \mathrm{Ci} / \mathrm{ml}$ was added for each $100 \mathrm{ml}$ of culture. These subcultures were incubated for $2 \mathrm{hr}$ in different light regimes before cell 
samples were collected and arialyzed for 14C incorporation.

Light intensity, or photon flux density, was regulated by wrapping culture flast:s in fiberglass screening and placing all flasts in a $22^{\circ} \mathrm{C}$ water bath with a 295 MEinstein'm2/sec cool-white light source belöw. Three light intensities were selected, two at subsaturating intensities where photosynthesis is a linear function of 1 ight, and one at a saturating light interisity where the photosynthetic response to light is nonlinear. Each layer of screening reduced photon flux density by half withaut affecting light quality (spectrum). All cultures were removed from the light field upon completion of iricubation. 14C samples were collected by vacuum filtration (S psi) onto GF/A filters and placed in $22 \mathrm{ml}$ glass liquid scintillation (LS) vials where they were allowed to air dry overnight. Eight ml of Solvent Free liquid scintillation cocttail (Isolab, Inc.) were added to the LS vials and these samples were counted in a Eect:man, Liquid Scintillation Counter.

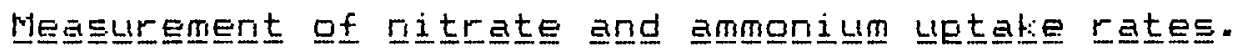
When nitrate and ammonium luptale rates were examined as a function of iron concertrations in the medilu, initial nitrate concentrations in the Fraquil medium were reduced by $95 \%$ to 10 H. These $10 w-n i t r a t e ~ c u l t u r e s$ were also grown with iron concentrations ranging from 0.01 to 1.0 fM for 7 to 10 days prior to experimertation. If nitrate uptate 
rates were to be examined, each culture was enriched with a small amount of $0.1 \mathrm{M}$ KNOJ sufficient to produce ca $10-50$ MM nitrate concentratione 24 hr before the experiment to induce nitrate reductase activity (Christenson, 1935). If ammonium uptalie rates were to be determined, a small volume of 0.1 . NH4Cl was added so that all cultures had equal nitrogen concentrations before experimentation. Each culture was enriched again with FNOS or NH4Cl approximately 50 minutes before the initiation of the experiment and placed in dartriess. Time zero samples of ritrate, nitrite, arid or ammonium as well as chloroptiyll a were collected from cultures by vacuum filtration. Cultures were wrapped in fiberglass screening and incubated at $0,27,53$, and 170 HEinstein'm2/sec. Samples were collected again after the 2 hr incubation period. Nitrate, nitrite, and ammonium coricentrations were determined by removing cells with filtration onto Wriatman GF/A 91 ass fiber filters and analyzing the filtrate colorimetrically. Rates of photosynthetic $14 \mathrm{C}$ fixation were also determined from the filtered cells if cultures were also spiled with NaH14CQS at time zero.

Nitrate coriceritrations in the medium were measured by reduction to nitrite and analyzed colorimetrically Gones, 1994). Nitrite was also measured in this manner excluding the reduction process. Ammonilum was determined 
colorimetrically uEing a modified phenol-hypochlorite method (Wetzel and Likens, 1979). Analysis was performed using a Gaush and Lomb Spectronic 100 spectrophotometer and prepared standards.

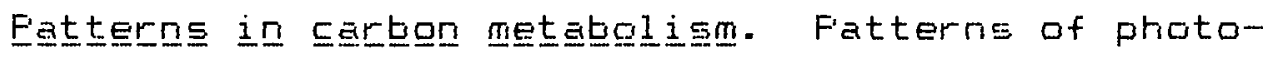
synthetic carbon metabolism were examined by fractionation of the 14C-labelled photosynthate using a slight modifiction of Morris:(1974) technique. The process involves the sequential separation of the hot ethanol-soluble, hot trichloroacetic acid-soluble, and insoluble fractions which respectively comprise the lipid-low molecular weight metabolite, polysaccharide, and protein-nucleic acid fractions.

14C-1abelled cells that were collected by filtration onto GF/A filters for photosynthate fractionation were placed in LS vials. Three $m l$ of $80 \%$ ethanol were added to each $v i a l$ and samples were stored in dartiness at $-140 \mathrm{C}$ for further extraction. Stored samples were later placed upon a glass filtration apparatus $(2.5 \mathrm{~cm}$ diameter Milipore) and 5 $m$ l of boiling absolute ethanol were filtered through gravitationally. Two ml of a cold ethanol rinse were vaculmed through the filter and the entire ethanol soluble filtrate was added to the original $\Sigma$ mil of $80 \%$ ethanol. This fraction was identified as the lipid-low molecular weight (LNW) metabolite camponent. 
The filter was placed in a second LS vial and $\Xi \mathrm{ml}$ of $5 \%$ (w/ $w$ ) trichloroacetic acid (TCA) were added. The vial was loosely capped and placed in a water bath and boiled for 30 minutes. The hot TCA was poured through a second GF/A filter which retained any TCA insolutle material or portions of the original fiber filter. The original filter was rinsed with $2 \mathrm{ml}$ of cold $5 \%$ TCA and the rinse was then filtered through the second filter. Eath GF/A filters were air dried (which was facilitated with a bow or $150 \mathrm{w}$ incandescent bulb) in LS vials before 5 mil of LS coctitail were added to each for counting.

One $m l$ of etharal and TCA solute was transferred to separate LS vials and $5 \mathrm{ml}$ of LS cocktail were added. TCA and ethanol are not readily miscible in the LS cocktail and required 24 hr for phase breatdown and emulsification. The photosynthate fractionation and total 14C uptate samples were analyzed with a Eecluman liquid scintillation counter. Fesults were reported as counts per minute. A summary of the extraction process is shown in figure 2. 


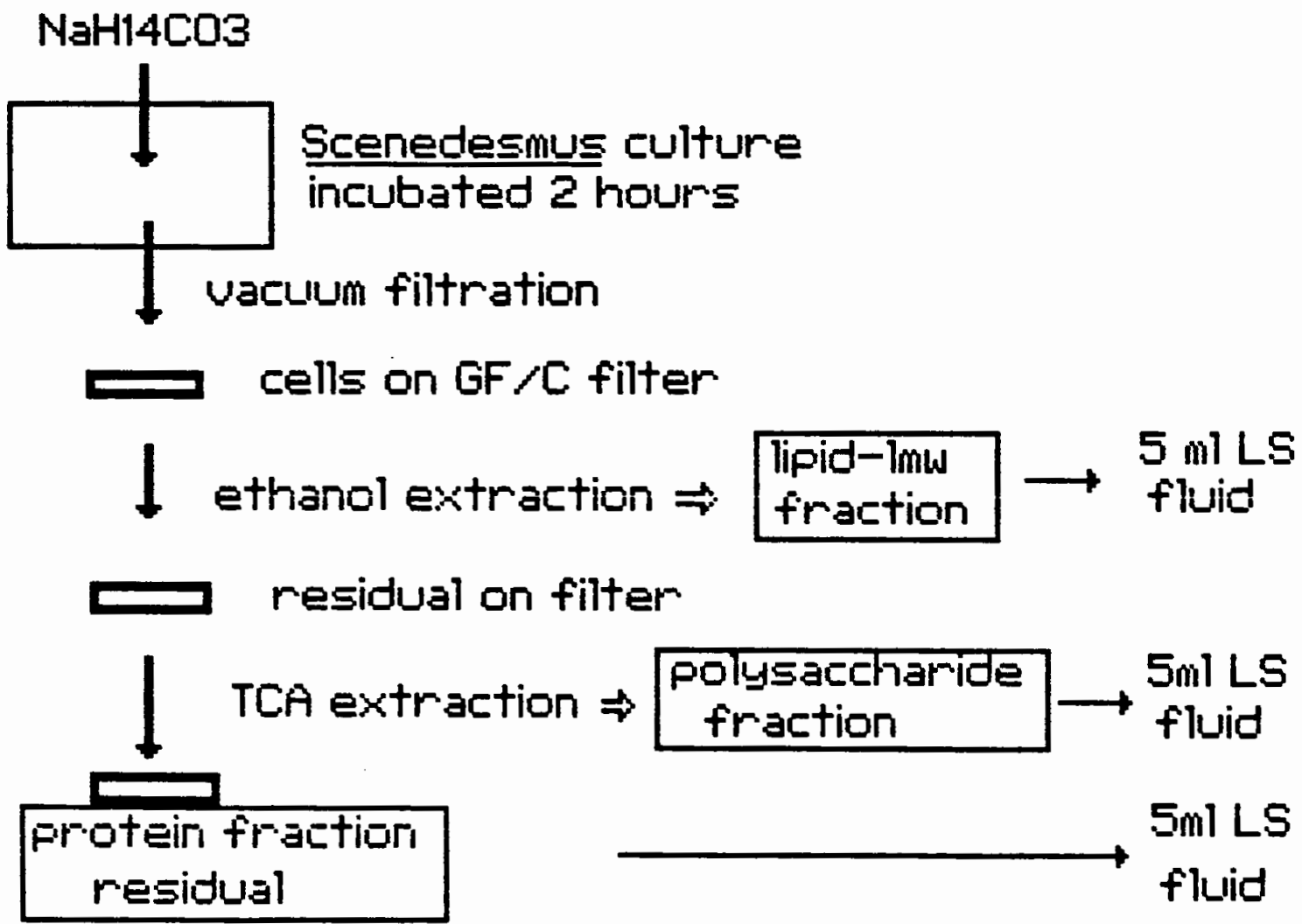

Eigure 2 . The sequential extraction 14C-1 abelled cellular components. LS-liquid scintillation: TCA trichloroacetic acid; $1 \mathrm{mw}-1$ ow molecular weight cellular comporients. 
CHAFTEF: I I I

THE INFLUENCE OF IFION AVAILAEILITY ON FHOTOSYNTHESIS IN SCENEDESMUS QUAADEICAUDA.

INTFIODUCTION

Fieductions in chlorofityll a and other light-harvesting pigments have been observed in iron-deficient algae coquist. 1971; Glover, 1977; Guikema and Sherman, 1983; and Muel1er: 1985). Changes in thylatoid membrane composition which produce Ehifts in chlorophyll absorption maxima in bluegreen algae have also been attributed to low-iron nutrition (Dquist, 1971; and Guikema and Sherman, 1985). Accompanying such changes in the 1 ight harvesting apparatus of these algae have teen increases in chlorophyll fluorescerice and reductions in 1 ight-harvesting capacity.

Fieductions in the photosynthetic protein content of iron-stressed protaryotic and eutaryotic algae have also been reported. Moderate reductions in iron nutrition were shown to decrease the iron-sulfur protein concentration in photosystem I of a blue-green alga without affecting growth rates. Severe iron deficiericy, however, brought about a decrease in photosynthetic cytochromes which interferred with photosynthetic electron flow and growth rates isandmann 
and Malkin, 1983). Cytochromes in the photosynthetic electron transport pathway were also sensitive to iron nutrition in a marine dinoflagellate, and this seneitivity was manifested in photosynthetic rates and efficiencies (Glover, 1977).

Similar reductions in light-harvesting pigments and photosynthetic proteins may also be expected in iron-

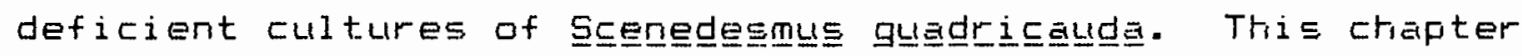
will report the effects that iron nutrition has on chlorophyll a concentrations, chlorophyll fluorescence, and photosynthesis. The role light intensity has in accentuating or ameliorating iron deficiencies will also be examined.

NETHODS

Subsamples of $10 \mathrm{~g}$ growth phase cells of Scenedesmus

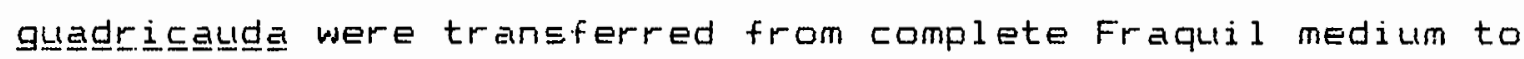
medium in which iron concentrations ranged from 0.01 to 1.0 MM. EDTA-chelated iron was used for all experiments. Experimental cultures were incubated at $22^{\circ} \mathrm{C}$ with continuous light at 100 MEinsteinsimz/sec in erlenmeyer flast:s for 7 to 10 days during which time cell densities and cellular fluorescence capacities were monitored.

Chlorophyll a samples were collected from each culture for later extraction with acetone and fluorometric analysis (Farsons, et al. 1984). Cultures were then equaliy divided 
into subcultures and wrapped with fiberglass ecreening.

These subcul.tures were then transferred to a second

incubator with a $220 \mathrm{C}$ water bath and a $275 \mu$ Einsteinsimzisec light field. Light intensity to each culture was regulated with the layers of screen wrapped around each flask. Light intensities of 27,55 , and 170 uEinsteins/m2/sec were used for experimental incubations. Photosynthetic response is a linear function of light intensity for the two lower-light regimes of 27 and $5.3 \mu$ Einsteins/m2/sec. Light is saturating at $170 \mu$ Einsteins/m2/sec. Dark cultures were incubated in double-layered black plastic.

NaH14COS, with an activity of $5 \mu \mathrm{Ci} / \mathrm{ml}$, was added to each subculture at $50 \mu$ per $100 \mathrm{ml}$. These additions were staggered to allow for equal incubation periods. Labelled cells were vacuum-filtered at 5 psi onto Whatman GF/A filters and air-dried in LS vials. Solvent Free liquid scintillation solution (Isolab, Inc.) was added to these filters and net $14 \mathrm{C}$ uptake was determined with a Eeckman scintillation counter.

FESULTS

\section{Chllorgetyyl 1 a. Chloraphyll a concentrations} demonstrated a functional response to iron concentrations in the experimental culture medium; increasing as iron 
concentration in the Fraquil medium increased from 0.01 ph to $1.0 \mathrm{MM}$ (Figure 3 ). Fiesponse to greater iron availability is seen as a gradual increase in chlorophyll a concentrations. There was no evidence of a sudden jump ir: concentrations which might be expected if chlorophyll synthesis was completely repressed by iron deficiency. This same trend in chlorophyll a concentrations was seen in other experiments.

A slight depression in chlorophyll a concentration was observed in the O.J MM iron culture. This depression may be due to greater rutrient deficiency in this culture than in other experimental cultures. Culture density in the 0. HM Fe culture was 12\% greater than other cultures. Since all cultures were initiated with an inoculum of equal cell density, greater growth rates arid therefore greater nutrient depletion must have accured in the 0.3 MM iron culture. This greater nutrient depletion depressed the chloroptiyl concentration in this culture.

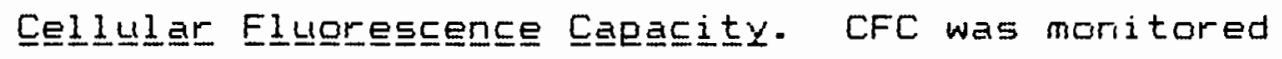
frequently during the incubation of cultures in experimental medium. Lower $\underline{i} \underline{n} \underline{v} \underline{i} \underline{v} g$ fluorescence relative to DCMU-induced fluorescence produced higher CFC values in iron-replete cultures (Figure 4). Lower CFC values in the iron-deficient cultures suggests that more photon energy captured in photosystem II is lost as fluorescence in these cultures than in 


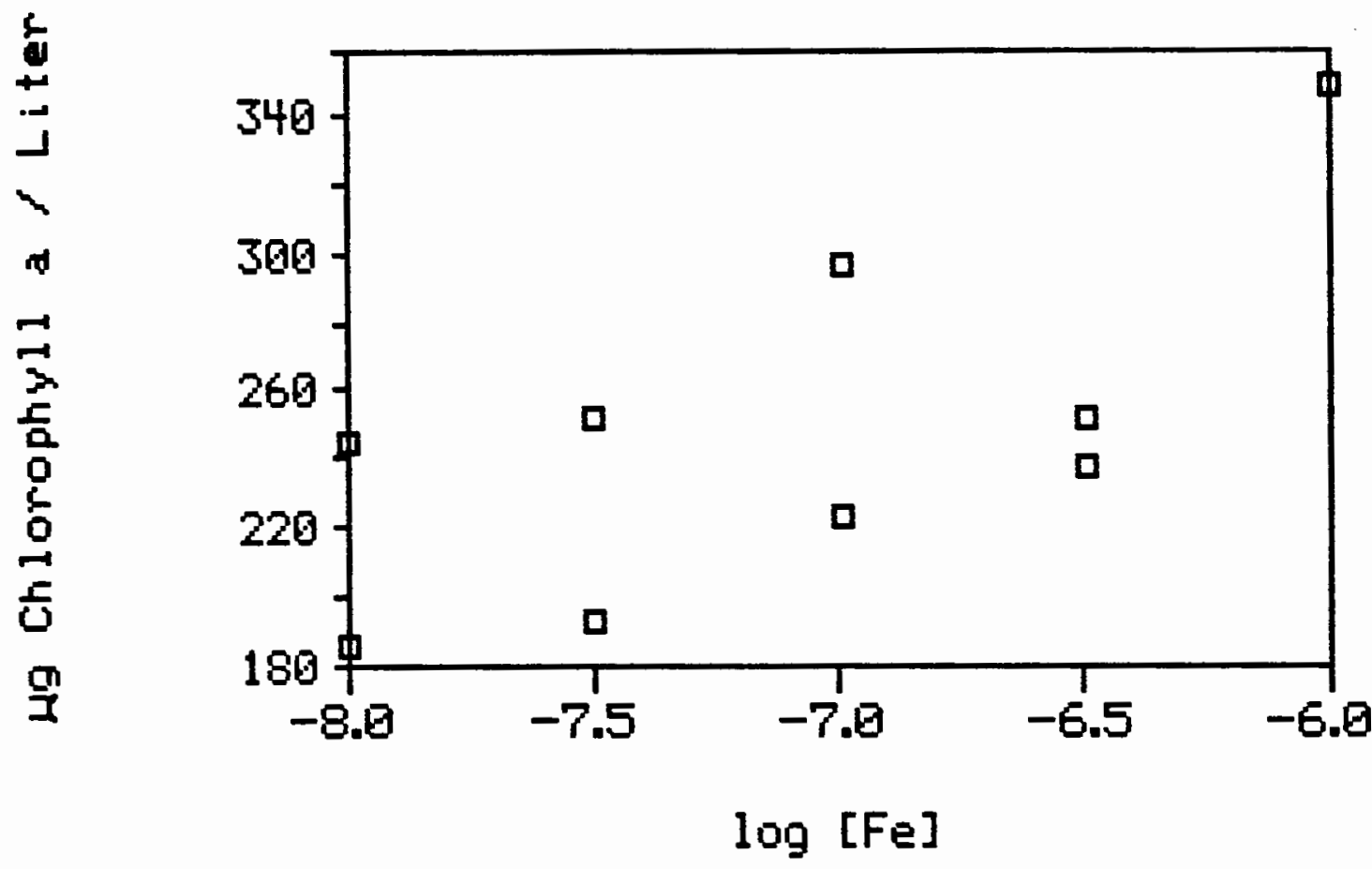

Eigure $\mathbf{S}$ - Chlorophyll a concentrations increase as a function of iron concentration in the media. The $\equiv l i g h t$ depression at 0.5 MH Fe (log value $=-6.5$ ) may be due to greater cell density and nitrogen depletion in this culture. The figure represents results from a single experiment which illustrates a general trend seen in other chlorophyll a extractions. 


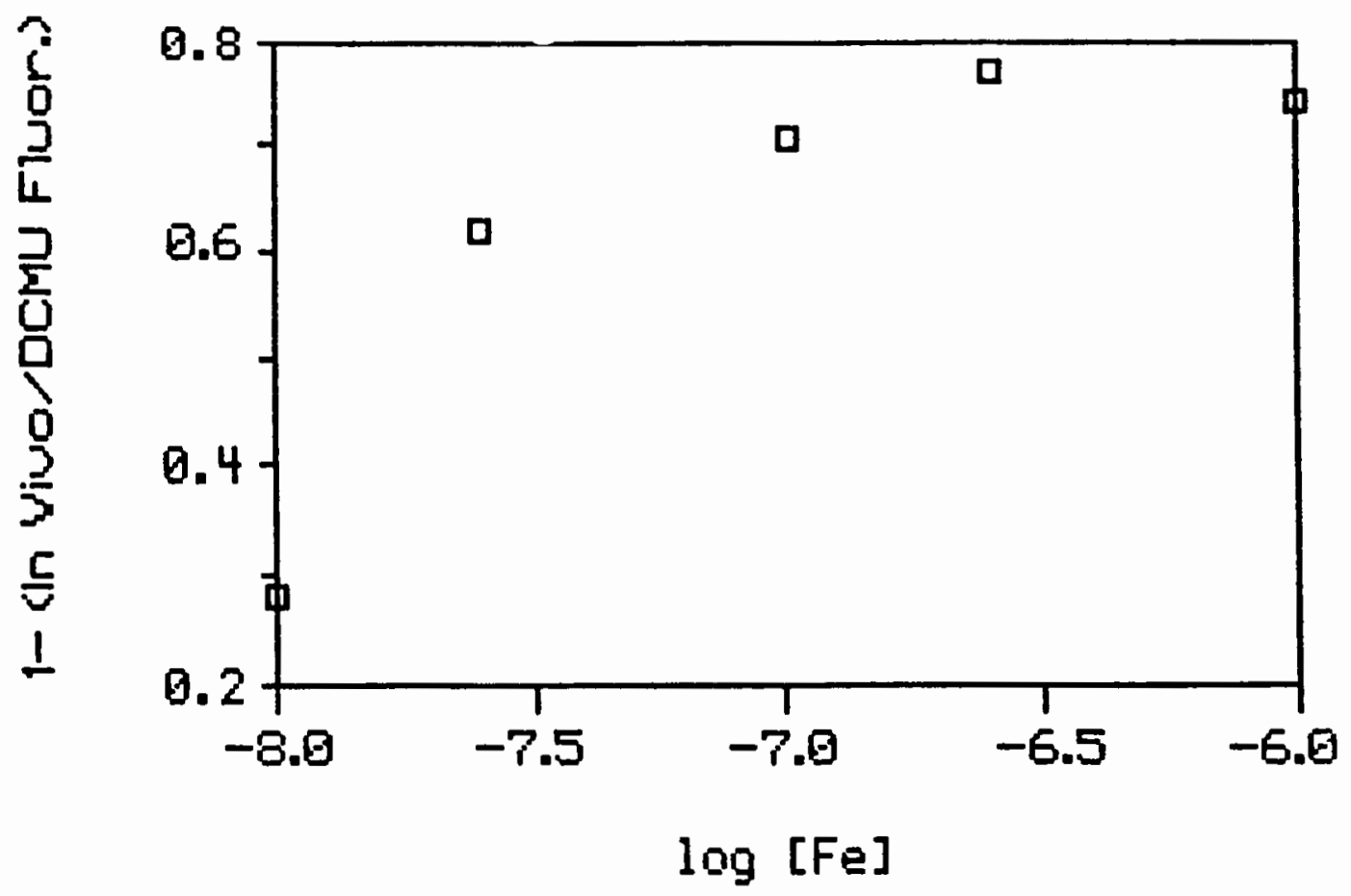

Eiquuㅡㄹ 4. Cellular fluorescence capacity $(1-\underline{i}$ - $\underline{\text { vivg }}$ fluarescence/DCMU-induced fluorescence) increases with greater iron sufficiency. Lower CFC values indicate greater in vivo chlorophyll fluorescence. Values are highly variable but maintain this pattern throughout the 7 to 10 day incubation period. 
iron-sufficient cultures. C.FC values less than 0.0 , such as the low value seen in the 0.01 uM (10-9 M) iron cul ture, are generally found in scenescent, or otherwise physiologically unfit cultures.

Fluarescence indices are especially sersitive to nitrogen deficiency and this is reflected in the variability of CFC values, which can change considerably during the incubation period as nutrients in the medium are depleted. Frequent dilution of the experimental cultures, or the transfer of cultures to fresh medium, may have decreased but did not eliminate this variability.

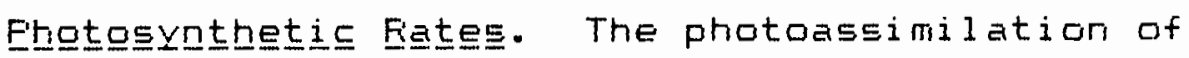
inorganic carbon shows a strong dependence on iron and light availability (Figure $\Xi$ ). The optimal iron concentration for carton fixation at all levels of photon flux dersity is observed at $0.3 \mu M$ while minimum rates are observed in the low-iron cultures 10.05 uM and 0.01 uM $F e)$. Cultures incubated with 0.3 uM Fe frequently support greatest culture densities, growth rates, and CFC values. For the high-iron cultures, total productivity is actually greater than Figure 5 suggests because chlorophyll a concentrations are also greater in these cultures. Low-iron cultures, on the other hand, result in low chlorophyll a concentrations. low growth rates, and depressions in other physiological responses. 


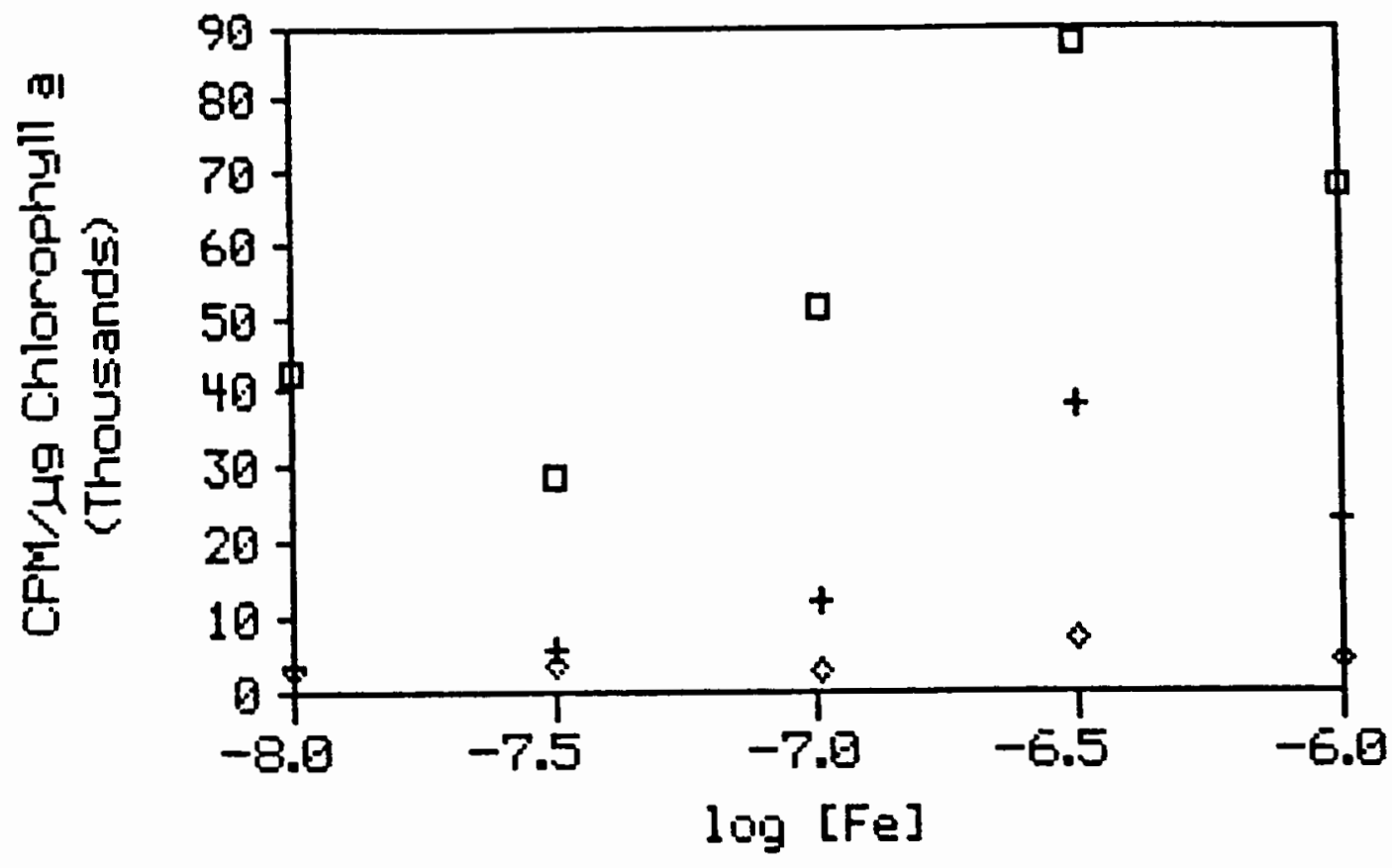

$0179 \mu$ Eins $/ \mathrm{m} 2 / s+53 \mu$ Eins $/ \mathrm{m} 2 / s \diamond 27 \mu$ Eins $/ \mathrm{m} 2 / s$

Fíg느르. 5 . $14 \mathrm{C}$ uptatie per chlorophyll a demonstrates a functional response to iron concentrations at all photon flux densities. Fhotosynthesis is light saturated at 170 HEins/m2/sec. tut is partially limited by light availatility at $5 \Xi$ and 27 MEinsimaisec. The influence of irradiance is mast pronaunced in iran-replete cultures. 
The influence of irradiance on carbon fixation is best seen in iron-sufficient cultures where a large increase in photosynthesis is observed with each increase in photon flux density. As iron deficiency becomes mare severe, the difference in carbon $f$ ixation at 27 and 55 HEinsteins/ma/sec decreases. Essentially no difference in $14 C$ uptatie is observed among $0.0 \mathrm{JM}$ and 0.01 LM Fe cultures incubated at these lower 1 ight intensities although large differences in photosynthetic rates are maintained at 170 LEinsteinsimásec.

\section{DISCUSSION}

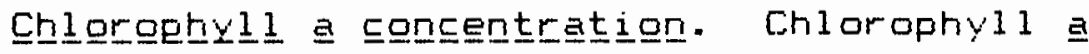
concentrations have been shown to be sensitive to iron availability in prolaryotic and eutaryotic photosynthetic algae 10quist, 1971; Guikema arid Sherman, 1983: Sandmann and Malkin, 1983; Glover, 1977). This sensitivity has been demonstrated al though irori is rot found in the chloroptyll molecule or it"s precursors. Chlorophyll synthesis is influenced by ferredoxin an iron-sulfur protein in photosystem I which functions as the primary electron acceptor in photosynthesis and requlates the distribution of photoreductant to metabolic pathways. Ferredoxin may activate the synthesis of delta amino-levulinic acid which is incorporated into the porphyrin ring of the chlorophyll molecule (Miller et al., 1984). 
The relationship between chlorophyll a concentrations and iron suggests that the regulation of chlorophyll syrthesis is altered. Ferredoxir: like other iron-sulfur proteins in photosystem I, is sensitive to iron deficiency (Sandmann and Maltin, 1983). Flavodosin, an iron-free protein can carry out many of the reactions requiring ferredoxin, and may be substituted for ferredoxin during periods of iron deficiency. This substitution of flavodoxin for ferredoxin has teen seen in cyarophytes and the green alga Chlorella (Zumft and Spilier, 1971). Whether chlorophyll synthesis is directly limited by ferredoxin concentrations, or if $S_{\text {. }}$ guuㅡ므므드르믈 has a substitution merhanism similar to that seen in Chl logrell la and how effectively that replacement mechanism may operate, is unknown.

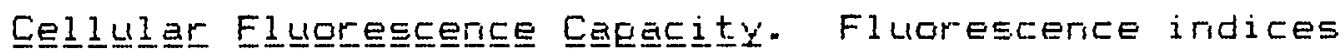
may reflect changes in the physiological state and ptotosynthetic caparity of an alga brought about by nutritional deficjencies (Frezlin, 1981). CFC is a measure of photosynthetic capacity relative to the structural and photochemical capacity of the cell (Vincent, 1990 ). Electron transport between the two photosystems has been identified as a rate limiting step in photosynthesis and is also sensitive to iron availability (Glover, 1977). Increased chlorophyll fluarescence in response to iron starvation has also been reported in cyanophytes ty 
Guitema and stieman (1983). It is 1 il:ely that iron deficiency decreases CFC by reducing the concentration or operating efficiency of iron-proteins in the electron transport system, creatirg an imbalance in the photosynthetic apparatus of an alga. Such an imbalance results in greater energy loss as fiuorescence.

Fhotogynthetí Eigte․․ The ability of an alga to maintain itself autotrophically is limited by environmental and physiological constraints. A reduction in photosynthesis trought about by a decrease in iror availability may be compensated for with an increase in irradiance. Similarly, increased iron availability may also compensate for decreased irradiance. Maderate reductions in two or more resources, however, can decrease photosynthesis to the point where cell maintenarice requirements are not met. This may have been seen when experimental cultures were started with a small inoculum: growth rates in irondeficient and nitrogen-deficient cultures were so low that cell densities sufficient for experimentation were rever ottairied.

Frotosyrithetic carbon fixation rates for $\underline{\underline{S}}$

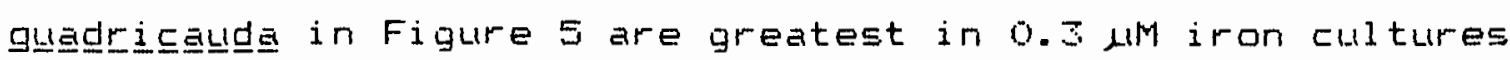
and decrease considerably at higher and lower iron concentrations. Inhibition of photosynthesis at high iron concentrations may be a toxic response to iron, or an 
artifact of batch culturing. Although high iron

concentrations may decrease algal productivity because of toxicity (Huntsman and Sunda, 1980) or complex chemical reactions which decrease the availability of some other essential nutrient such as phosphorus (Storch and Duntiam. 1986), it is more litely that nitrogen was rapidly depleted resulting in lower carbon fixation rates.

Fhotosynthesis is most efficient when cells are well adapted to the prevailing irradiance. Chlorophyll to protein and photosystem reaction centers ratios il.E." F $680: F 700$ ) are optimized to capture and transfer photon energy. Iron deficiency has been demonstrated to bring about a reduction in photosystem I proteine, F700 reaction centers, and the heme-bearirig cytochromes of the phatosynthetic electron transport system in maririe chloroptiytes (Glover, 1977) and blue-green alga (Sandmanin and Malkiri, 1985), with a correspording decrease in photosynthetic capacity (Qquist, 1971; and Terrys 1985).

Feports of iron-limited productivity, or increased productivity in iron-enrictied waters are found for freshwater and oceanic systems Goldman, 1973; Erand et al., 1935; Glover, 1977; and Miller et al., 1974). Fiesponses to iron deficiency that increase in vivo chlorophyll fluorescence (decreased CFC) also diminish carbon fixation rates. Concomitant reductions in chlorophyll, cytochrome 
and F7o0 proteins, may dramatically reduce photosynthetic efficiency and capacity, thereby providing little of the photochemical energy required for carbon fixation.

Carbon fixation rates can also be examined relative to prevailing irradiance (Figure b). Froductivity when examined as a function of photon flux density provides a carbon assimilation value per photon ard is dependent on iron concentrations. This assimilation value is similar to photosyritretic efficiency ard can te compared with CFC (Figure 7) to demonstrate the relationstip between cellular fluorescence capacity and photosynthetic tehavior. Strorg relationships between photosynthetic efficiercies and fl. worescence indicies such as this have teen reported elsewhere isamuelsson and Qquist, 1977; and Frezlin and Ley 1980).

CONCLLUSION

S. gㄴadrí드네요 responds to iron deficiericy with a reduction in chlorophyll a concentrations, cellular fluorescerice capacity and photosynthetic rates. Chlorophyll a coricentrations are considerably greater when cells are grown at 1.0 lly iron concentrations than when grown at 0.01 s.M. CFC is highly variable but maintains a positive relationship to iron concentrations throughout experimental inclbation periods of 7 to 10 days. Short-term 


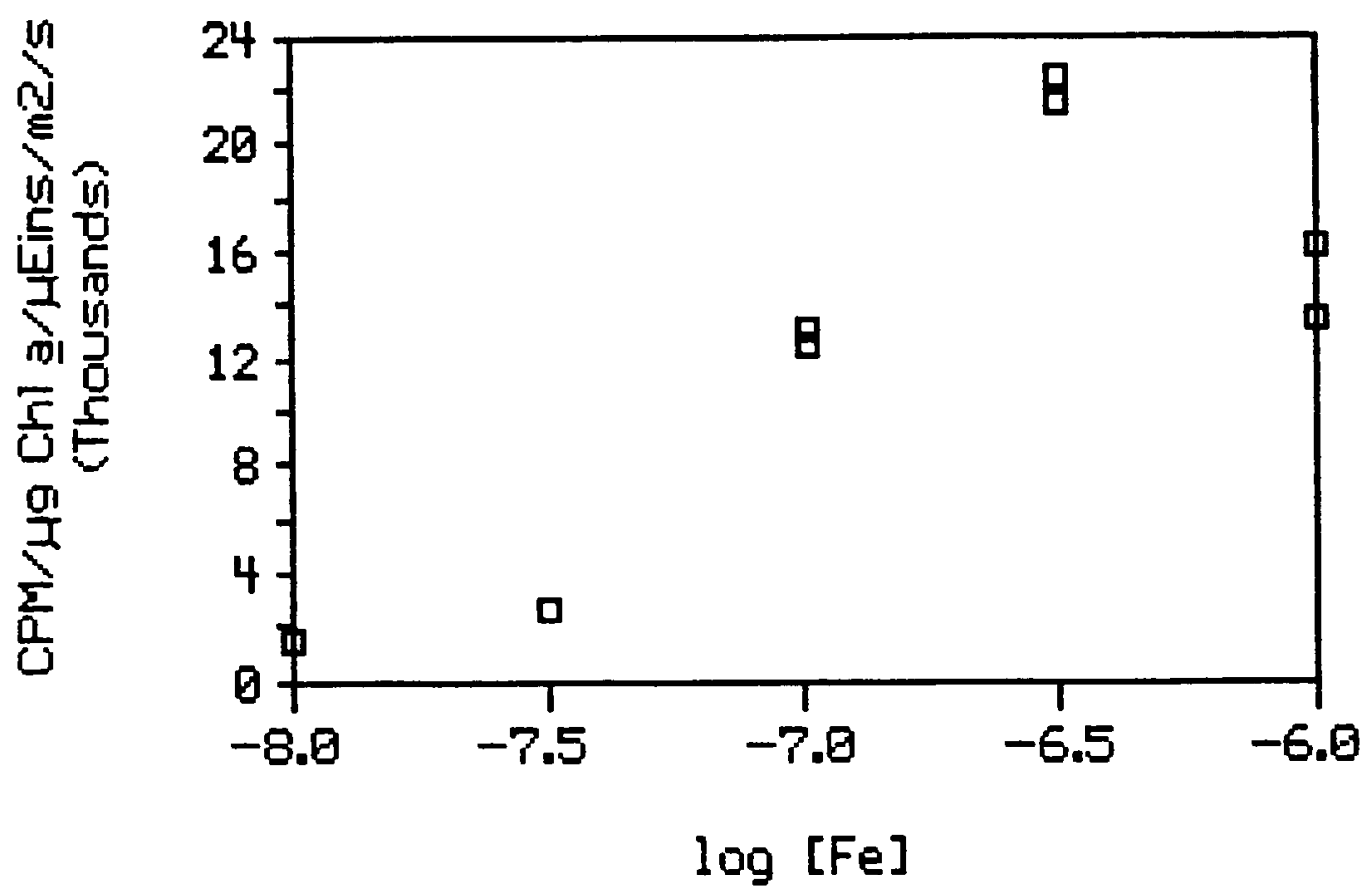

Figure 6. 14C uptake per chlorophyll a relative to photon flux density indicates that carbon assimilation or photosynthetic efficiency is controlled by iron nutrition. 


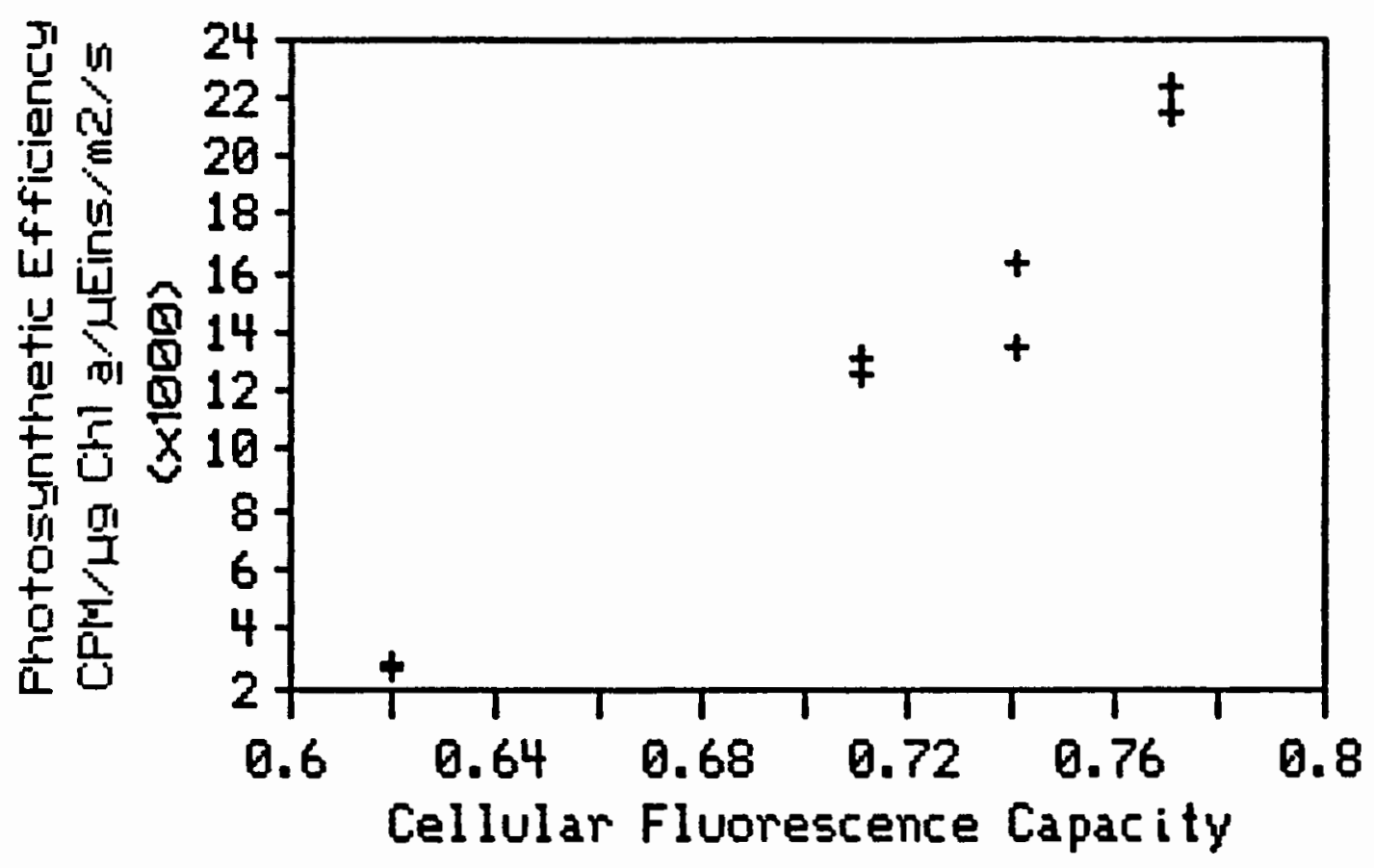

Eigure 2. Fhatosynthetic efficiency is linted to celiular fluorescence capacity. Feductions in chloroptyll fluorescence allow for greater carbon assimilation efficiencies. The data here were callected fram cultures incubated at $27 \mu$ Eins/m2/sec. 
photosynthetic carbon fixation rates also respond to iron concentrations in the culture medium. Fhoton flus derisity strongly affects the rate of carbon fixation and may compensate for moderate iron deficiencies. A strong relationship between photosynthetic efficiency and cellular fluorescence capacity is seen. 
CHAFTEF: IV

THE EFFECTS OF IFON DEFICIENCY ON NITFOGEN METAEOLISM AND SOME FHYSIOLOGICAL FESFONSES

\section{INTFIODUCTION}

Despite the continual influx of nitrogen from terrestrial and atmospheric sources and the internal recycling of mutrients within the aquatic ecosystem, the primary productivity of the oceans and some oligotrophic lates is thought to be 1 imited by ritrogen availability (Smith, 1984). Nitrogen is of major metabolic importance in algae; it is found in such fundamental components as amino acids, nucleotides, and the porphyrin containing pigments of chloroptiylls and cytochromes. Cell quotas for nutrients can increase when an alga is grown with low nutrient or light availatiltiy (Ftiee and Gotham, 1981). Simultaneous reductions in iron rutrition and irradiance may increase algal cell quotas for nitrogen while interfering with normal nitrogen metabolism, driving the algal population towards ritrogen starvation.

The patt of inorgaric nitrogen assimilation involves the movement of ione across cell membranes, reduction of nitrate and nitrite to ammonium, and the subsequent 
formation of glutamate in enzyme mediated processes which require ATF and reductant. Light is tightly linked to this Frocess although inorganic nitrogen uptake and assimilation can occur for some time in darbiness if sufficient carbohydrate reserves exist to produce ATF and reductant via respiration (Ull lich, 1983).

Lite light limitation, iror deficiency may hinder inorganie nitragen metabolism by diminishing the supply of reductant and ATF from photosyrithesis to the nitrogen uptatie and assimilation pathways. Nitrogen metabolism may also be retarded if carbon-eleletons which accept nitrogen to form glutamate are unavailable. In addition, important ironcontaining enzymes are also found in the pathways of nitrogen metabolism.

Algae grown in low-iron, low-light enviranments may be energetically stressed. Competition for photochemical eriergy amorig the various metabolic pathways will be intensified, decreasing rates of carbon assimilation, nitrogen metabolism and numerous other frocesses. Although ammonium is energetically more easily assimilated, algae readily assimilate both nitrate and ammonium, the two most important forms of inorganic nitrogen, coortch and Conway, 1984). This chapter will examine how iron deficiency arid irradiance affect the rate of nitrate and ammonium uptalie and how chlorophyl1 a concentrations arid photosyrithetic 


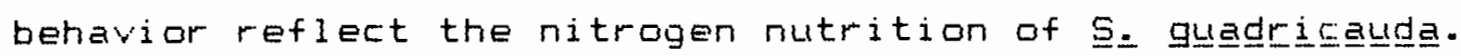

METHODS

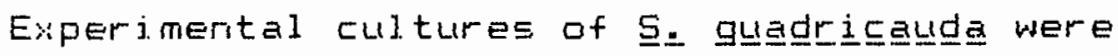
maintained in Fraquil medium with iron concentrations ranging from 1.0 MM to 0.01 M. Cultures were started with subsamples from stocks grown in complete Fraquil. Iritial ritrate concentrations in cultures used for nitrate and ammorium uptatie experiments were reduced from 200 um to 10 LM. Cultures were frequently centrifuged and transferred to fresti, iron-adjusted medium to prevent the depletion of other nutrierits.

Nitrate, nitrite, and ammonium concentrations were measured in the the cultures during the 7 to 10 day incubation period and before the beginning of the uptake experiments. Nitrite and ammonium accumulations in the growth medium will indicate inefficient nitrate metabolism and the loss of intracellular nitrogen. All cultures, including those used for ammonilum uptat:e experiments, were grown with ritrate as the nitrogen source.

Nitrate, ammonium, and $14 C$ uptalie experiments were started 7 to 10 days after transfer from the original stock: cultures. Nitrate reductase activity was induced with a small addition of $0.1 M$ KNOS about 24 hr before experiments were conducted (Christenson, 1983). A similar volume of 0.1 
M NH4Cl was added to cultures used for ammonium uptat:e experiments to insure that ritrogen concentrations in all cultures were approximately 10 to $50 \mathrm{\mu M} 24 \mathrm{hr}$ prior to Experimentation.

Time-staggered additions of small volumes of $0.1 \mathrm{M}$ KNOS or NH4Cl were again introduced into each culture 30 mirites before time zero samples were collected. Samples were swirled vigorously and immediately placed in dartiness to allow for complete mising of nitrate or ammonium before collecting time zero samples. Staggering nitrate ard ammonium additions insured that incubation periods were equal for all cultures considering the time required to filter samples. Time zero samples of chlorophyll a, nitrate and nitrite, or ammonium were collected in the order cultures cultures received these additions.

Cultures were divided into equal subcul tures, wrapped in fiberglass screening and spitied with 50 H NaH14COS per $100 \mathrm{ml}$ of culture after time sero sampling. The NaH14Cos had ari activity of $5.0 \mu \mathrm{ci} / \mathrm{ml}$. These subcultures were incubated at $22^{\circ} \mathrm{C}$ in a water bath with a 275 MEinsteins/m2/sec 1 ight source below. Layers of fiberglass screening produced light regimes of 170,53 , and 27 MEinsteins/m2/sec. Cultures were incutated for $2 \mathrm{hr}$. Nitrate, nitrite, ammonium, and 14C samples were collected in the sequence they were spilied. 14C-1abel led 
cells were vaculum-filtered ( $5 \mathrm{psi}$ ) onto Whatman GF/A filters and the filtrate saved in $50 \mathrm{ml}$ polyethylerie centrifuge tubes for nitrogen analysis. Eight ml of Solvent Free 1 iquid scintillation fluid (Isolab, Inc.) were later added to liquid scintillation vials containing the air-dried filters. $14 C$ uptale rates were estimated with a Eecliman liquid scintillation counter.

Nitrogen uptake rates were determined by measuring the depletion of nitrate or ammonium from the culture medium. Nitrate concentations were determired colorimetrically after reduction to ritrite with cadmilum and compared to a standard curve (Jones, 1984). Nitrite was also analyaed in this manner, excluding the cadmium reduction step. Ammonium was determined colorimetrically using a modifed phenol hypochlorite method (Wetzel and Likens, 1979). All colorimetric analyses were performed with a Eaush and Lomb Spectronic 100 spectrophotometer.

\section{RESULTS}

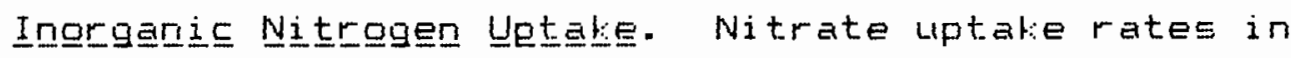
iron-sufficient cultures were much greater than rates observed in iron-deficient cultures (Figure 8). Light also clearly entianced ritrate uptabe, with greater uptatie rates seen in cultures incubated at 170 HEinsteins/m2/sec at all iron concentrations. As with carbor lutale in the 


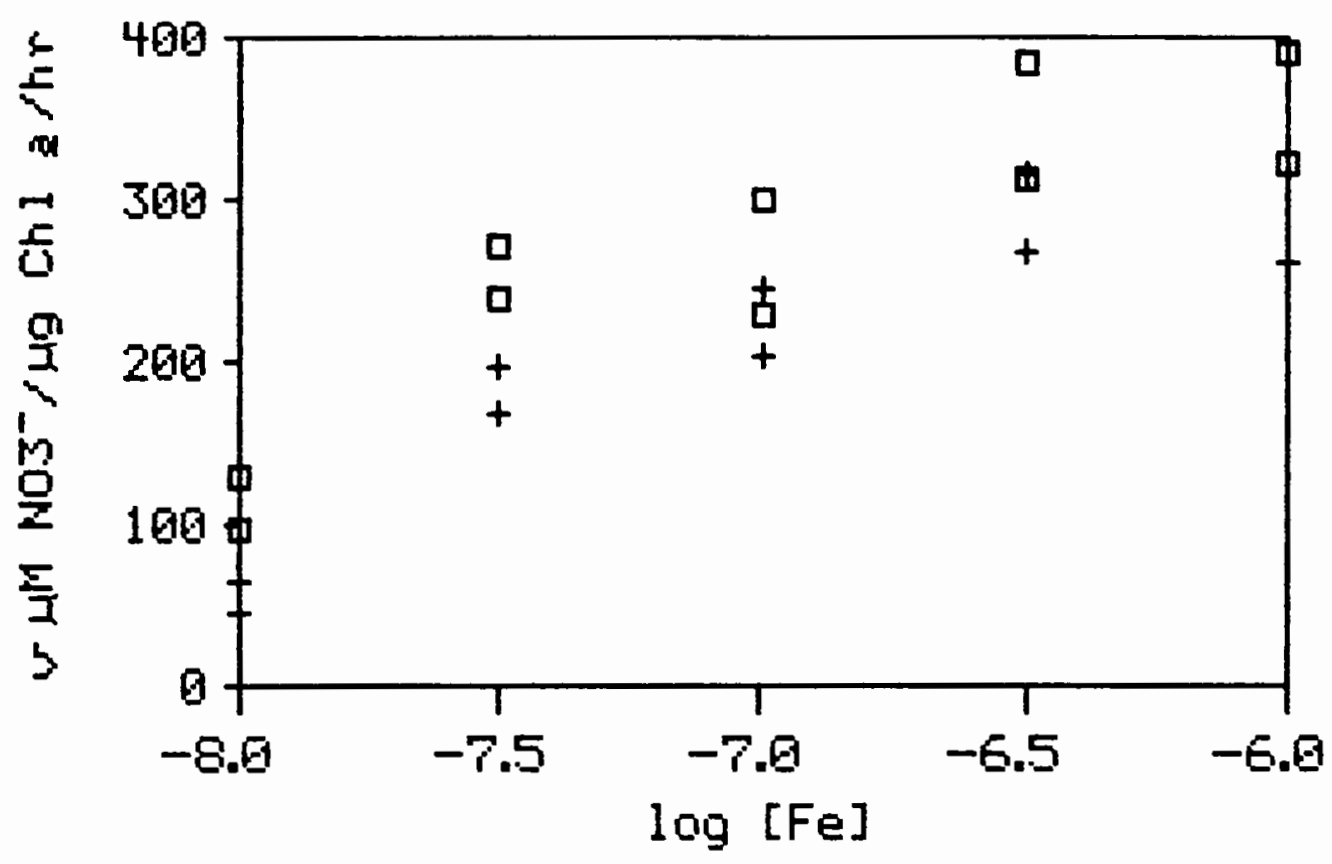

- $170 \mu \mathrm{Eins} / \mathrm{m} 2 / \mathrm{s}+53 \mu \mathrm{Eins} / \mathrm{m} 2 / \mathrm{s}$

Eiglure 8. Nitrate uptake rates fer chlorophyll a increase with greater iron nutrition and irradiance. Differences in total nitrate uptake are partially hidden by normaliaation to chlorophyll a. 
preceeding chapter, the much greater nitrate uptake rates in iron-replete cultures are partially hidden by normalization to chlorophyll a .

Ammonium uptake rates were also examined as a function of iron concentration and irradiance, however it soon became apparent that ammonium uptake occurs so rapidly that concentrations were below levels of detection at the end of the 2 hr incubation period. Consequently, a second series of experiments examined nitrate and ammonium uptal:e rates in cultures incutated for 30 minutes in complete darliness (Figure 9).

Nitrate depletion in the absence of light was generally greatest in iron-sufficient cultures with maximum removal of nitrate seen in $0.5 \mu M(109-6.5 M)$ iron cultures. Uptake rates were nearly the same in cultures of moderate and high iron deficiency.

Ammonium depletion from the medium is slightly greater in iron-sufficient, or moderately-deficient cultures than in iron-deficient cultures. Maximum uptal:e capacity is unknown in these cultures because ammonium concentrations were typically below the level of detection by the end of the 0.5 hr dart: incubation. It is possible that greater uptal:e rates may have been demonstrated by the iron-replete cultures if additional ammonium had been availatle. The sharp decline in ammonium depletion rates seen in the 0.05 uM Fe llog 


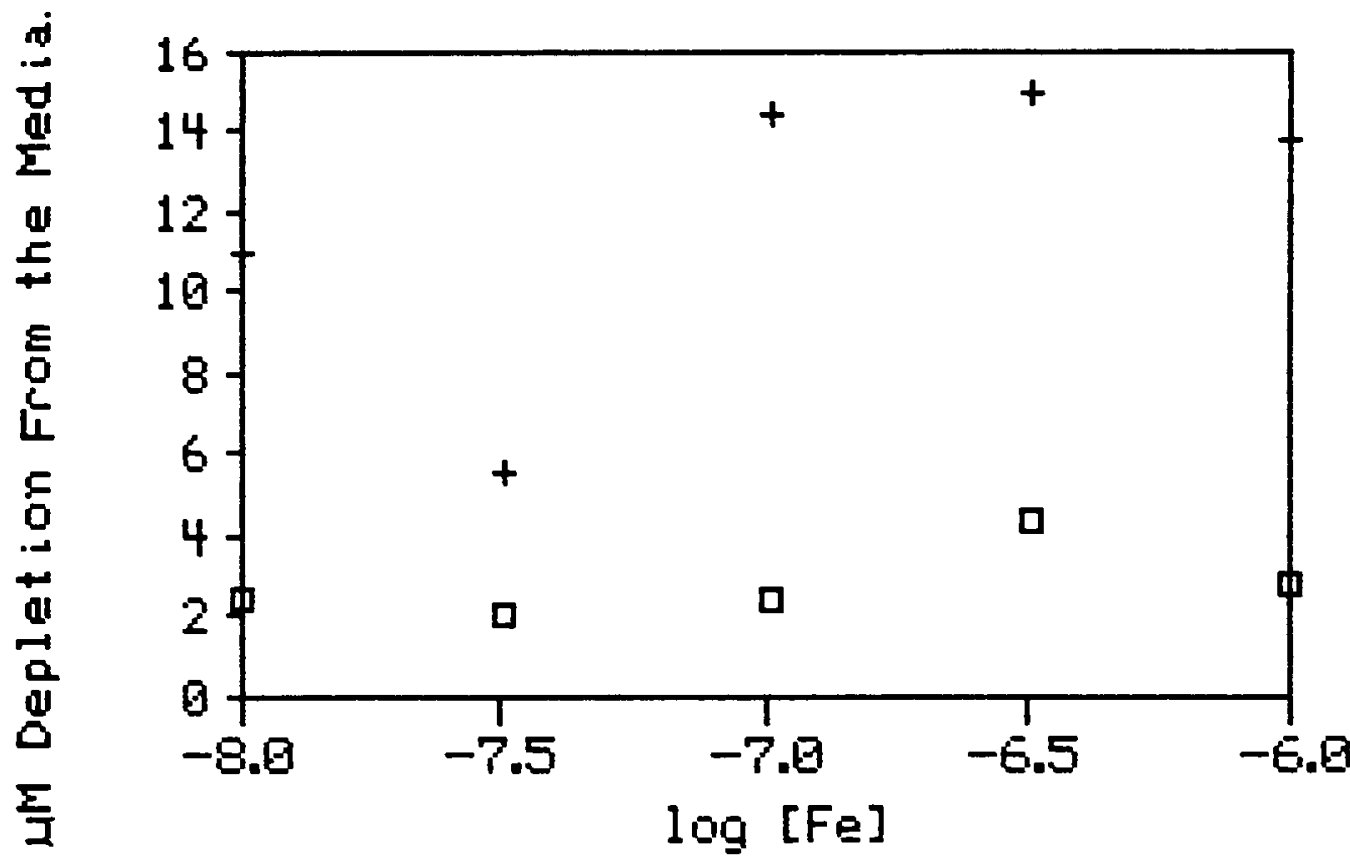

a nitrate

+ anmoniuin

Figuree 9. A comparison of nitrate and ammonium depletion from the culture media during a 30 minute dark incubation. Greatest depletion occurs in the 0.5 (M (109 $=-6.5$ M) iron culture. Values are not normalized to chlorophyll a and are the mean value of duplicate samples from a single experiment. 
value $-7.5 M$, culture may not be attributed to factors such as cell density or growth rates because a similar response was not also seen in nitrate depletion rates at this iron concentration and is probably an experimental artifact.

Large differences in nitrate and ammonium uptake rates are also seen when iron-deficient cultures $(0.01 \mu M)$ are ircluated at different photon flux densities (Figure 10). Ammonium uptatie rates are greater than nitrate rates at all levels of irradiance and appear to be iridependent of light intensity. Light has teen reported to be strongly Iinled to nitrate uptatie and this is seen at low photon flux density. At high irradiances nitrate uptake is light saturated and independent of photon flux density.

Accumulations of nitrite in the culture medium were not seen in at any level of iron nutrition. Nitrite was below the level of detection throughout the 7 to 10 day incutation period and after Experimentation with low light incubations. Similarly: no accumulatione of ammonium were detected in any of the iron-treatment. cultures grown on nitrate.

Chl gorophyl] ․ Chlorophyll a concentrations were examined in cultures grown nitrate-sufficient and nitratedeficient ( $200 \mu M$ and $10 \mu M$ respectively) with iron concentrations that ranged over two orders of magnitude $110-$ 6 to 10-8 $M$ Fel. A functional threshold exists which 


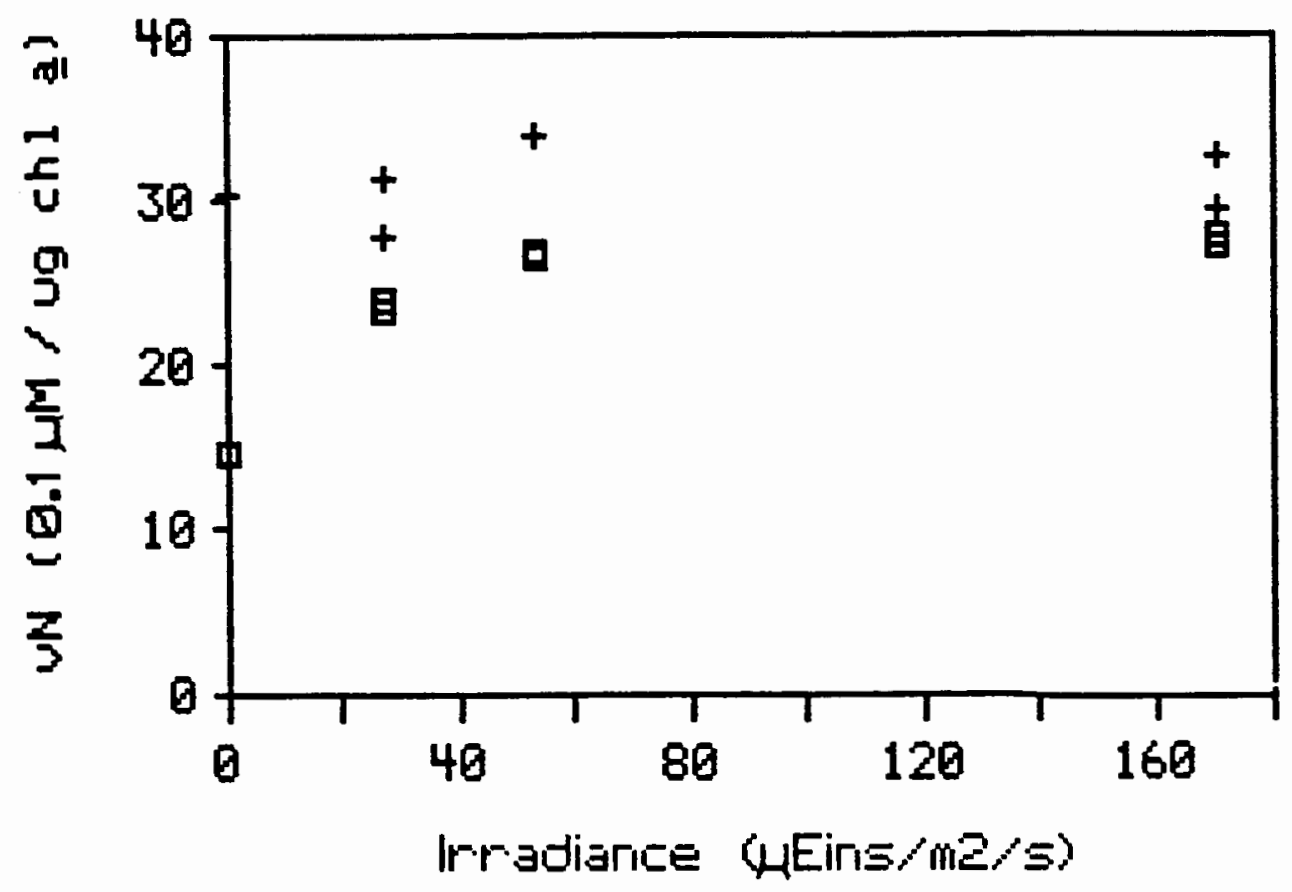

- nitrate + ammonicum

Eiguré 10. Nitrate and ammonium uptake rates as a function of irradiance or photon flux density. Nitrate uptake is 1 ight-saturated at 5.3 HEine/m2/sec and becomes a nonlinear function of light. Ammonium uptate is independent of irradiance. 
partitions the expression of each nutrient deficiency

(Figure 11). Iron deficiency is the predominarit factor regulatirg chlorophyll a concentrations in cultures grown with iron concentrations of 0.1 HM $(10-7 \mathrm{M})$ or 1 ess.

Chlorophyl a concentrations were escentially the same for both nitrate-eufficient and nitrate-deficient cultures grown at these lower iron concentrations.

Chlorophyll a concentrations in iron-sufficient cultures were a function of nitrate availability. Concentrations in iron-replete, nitrate-replete cultures were several times greater than concentrations in ironreplete, nitrate-deplete cultures. A distinct decline in chlorophyll a concentrations is observed in both nitrate deficient and sufficient cultures at the highest iron concentration (1.0 MM, $10-6 \mathrm{M} \mathrm{Fe).}$

Ehotogsynthetic Eates. Fhotosynthetic carbon fixation rates per chlorophyll a were examined in nitrate-sufficient and deficient cultures incubated over a range of photon $f u \%$ densities (Figure 12). Iron was not a factor in this experiment and all cultures were grown in iron-replete 110 -b M) medium. As seen in chlorophyll a concentrations, a physialogical threshold exists; high photon flux density compensates for nutrient deficiency ard carton fixation rates in nitrogen-deficient and nitrogen-sufficient cultures are nearly equal. Again however, because of the greater 


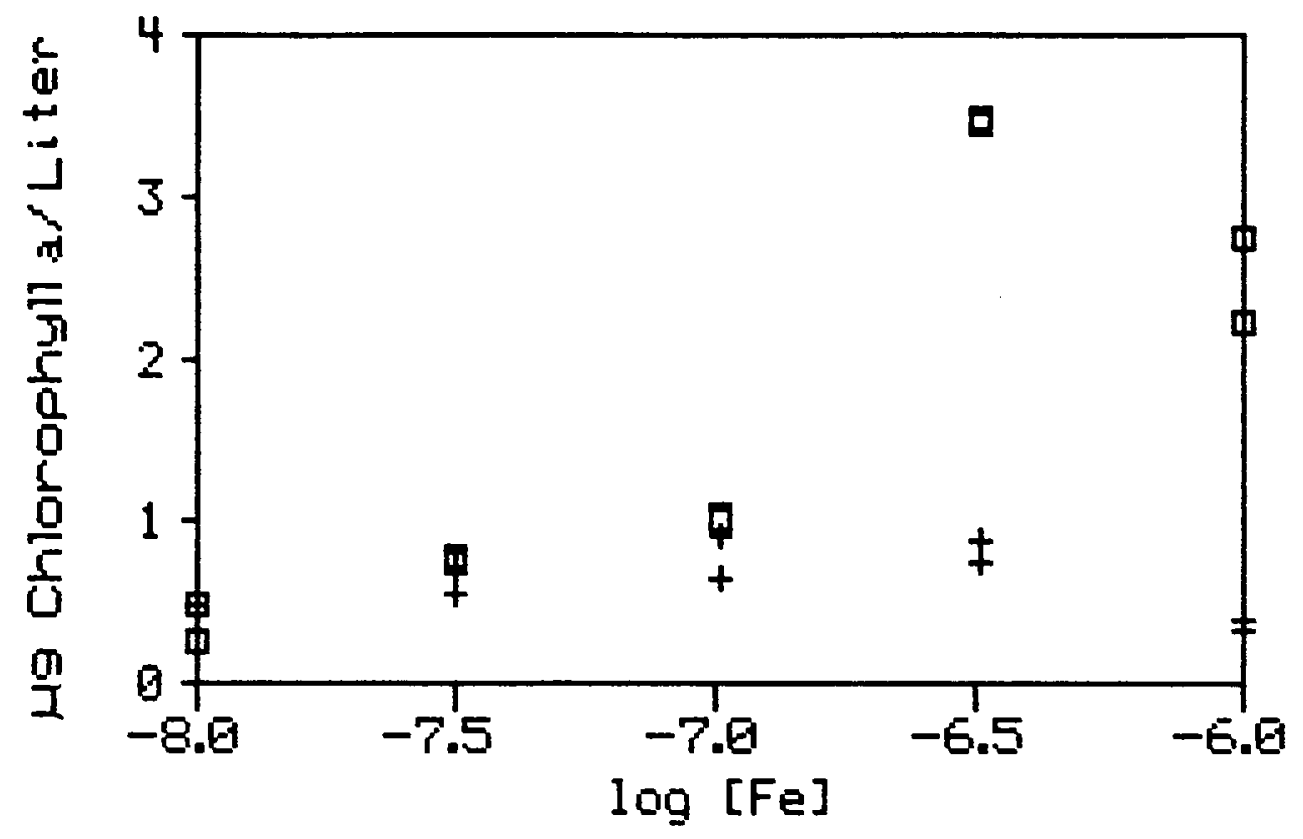

a nitrate replete + nitrate deplete

Fiqure 11. Chlorophyll a concentrations examined as a function of iron and nitrate nutrition indicates that iron nutrition more strongly controls chloraphyll concentrations than nitrate. Only in iron-replete cultures does nitrate nutrition determine chloraphyl a concentrations. 


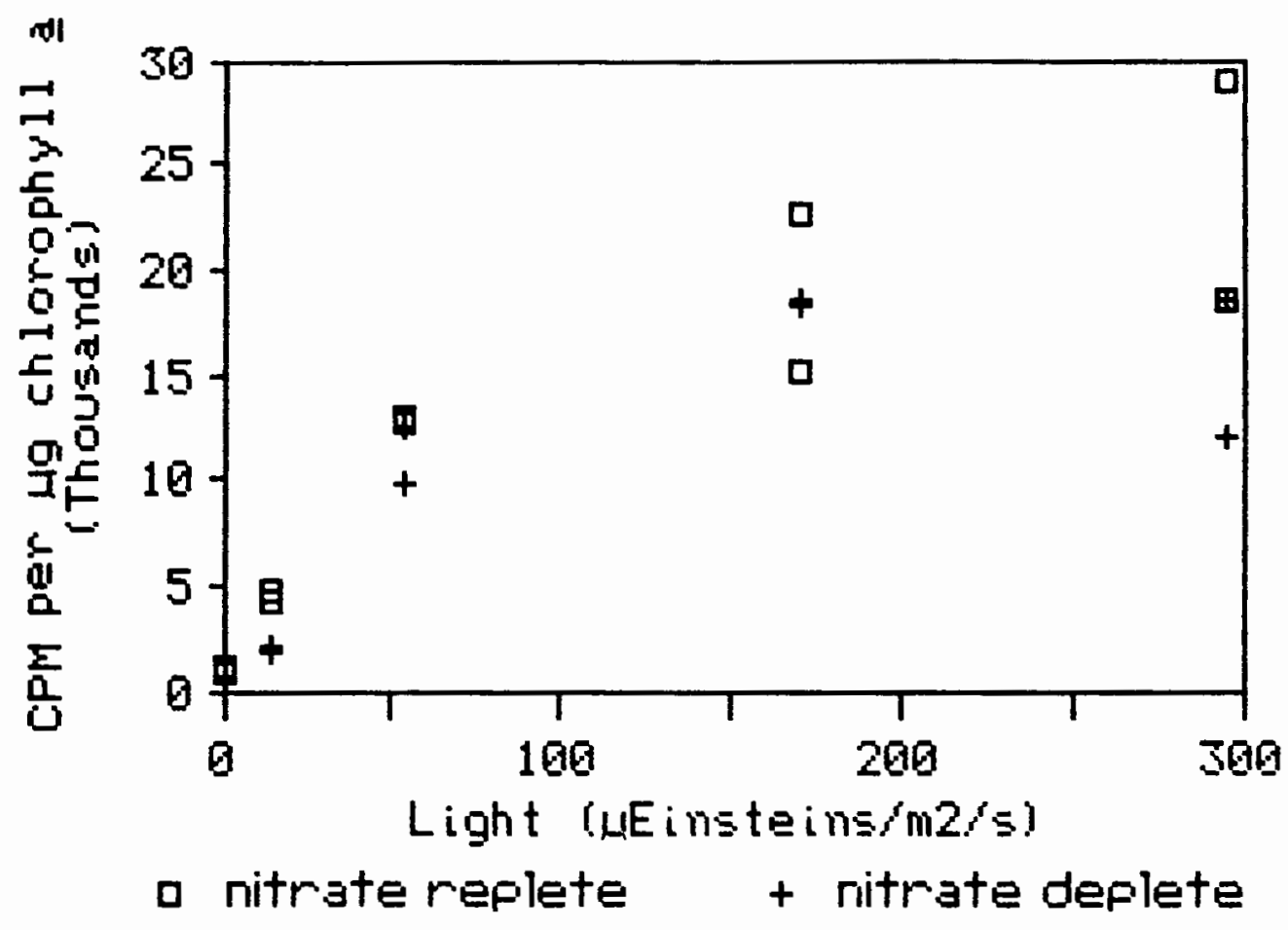

Eigure 12. The influence of light intensity and nitrate nutrition on $14 \mathrm{C}$ uptalie. Nitrate-refiete cultures have greater carbon assimilation efficiencies than nitratedeplete cultures. This is seen as a steeper slope in the region where carbon uptake is a linear function of irradiance. High light intensity mitigates for nitrate deficiency. 
chlorophyll a concentrations, net productivity is actually much greater in the nitrate-replete cultures. Nitrogen deficiency is accentuated at low-light intensity where carbon fisation is a linear function of irradiance. Carbon fixation in nitrogen-deficient cultures is considerably less than rates exhibited by nitrogen-sufficient cultures in these low-light regimes.

Carbon fixation rates were also examiried in cultures enriched with either nitrate or ammonium shortly before incubation with NaH14COS at different photon flus derisities (Figure 13). Cultures with ammonium as a nitrogen source demonstrated considerably greater carbon fixation rates than cultures with a nitrate-nitrogen source at all photon fluk densities. This greater photosynthetic activity is also reflected in the linear slope of the productivity curve (Figure 13).

\section{SCUSSION}

Nitrate uptate and assimilation is energetically costly to an alga requiring nearly half as much of the cell"s metabolic energy as carbon fixation (Syrett, 1981). Ions must be actively transported against a concentration gradient into the cell and reduced to ammonium in a series of processes consuming ATF and reductant. Nitrate is reduced to nitrite in the cytoplasm of the cell using reductant supplied by NADFH. Nitrite is then reduced to 


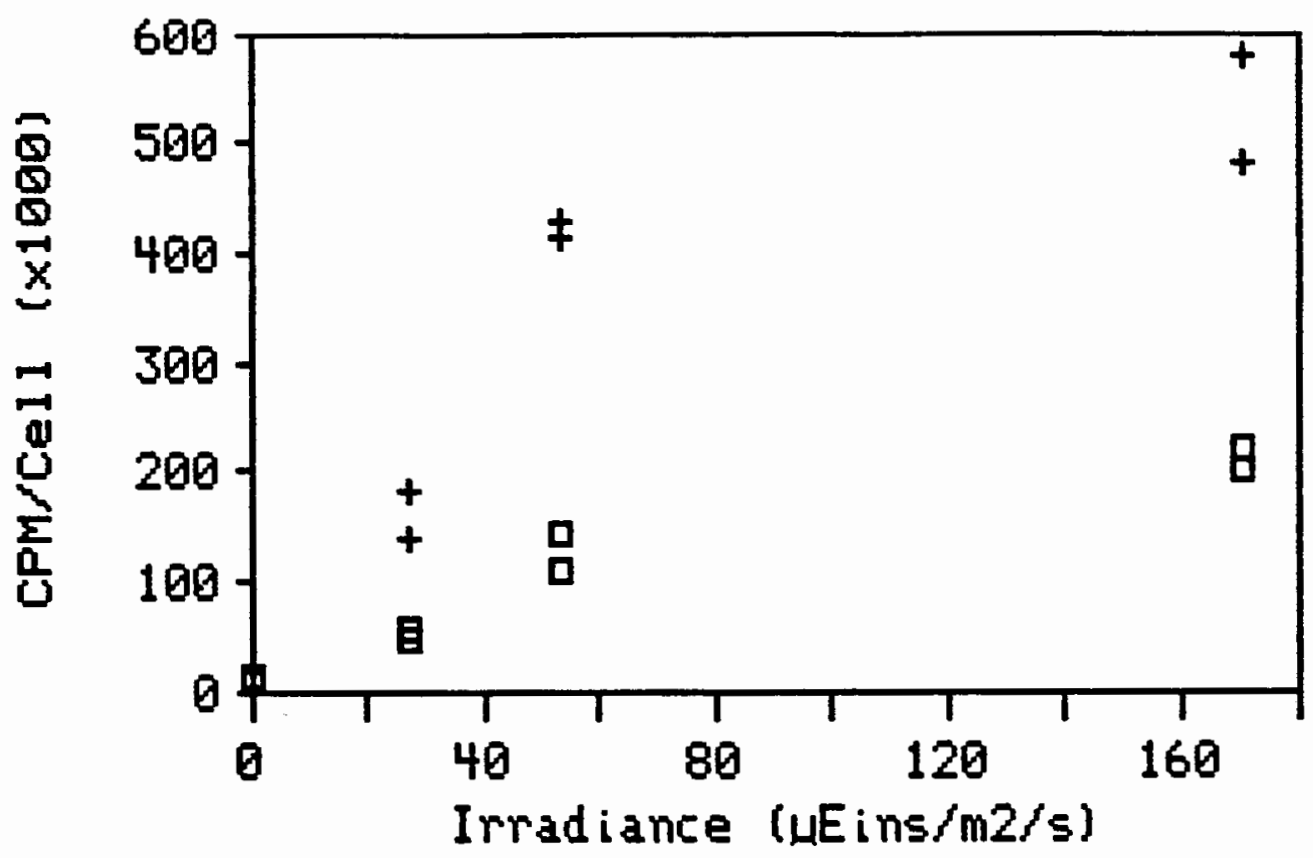

- nitrate + amimanium

Eigure 13. A comparison of the influence of ritrate arid ammonium-nitrogen sources on photosyrithesis. Cultures incubated with ammorium demonstrate greater 14C uptatie rates at all Iight intensities. Saturating light intensity 1170 HEins/ma/sec) does not compensate for the difference in nitroger sources. 
ammonium in the chloroplast where ferredoxin serves as the electron dorior. The glutamine synthetase' glutamate synthetase (GS/GOGAT) pathway, converts inorganic ammonium into an organic nitrogen compound (glutamate) which is available for the synthesis of nitrogenous organic molecules suith as amino acids, porphyrins, and other essential cellular components (Ullrich, 1983; see Figure 1). Iron nutrition arid irradiance influence nitrate metabolism in a similar manner. Iron sufficiency is required for an uninterrupted supply of photochemical energy to the nitrate reduction and assimilation enzymes. Irradiance is linled to nitrate metabolism for many of these same reasons. The light reaction of photosynthesis reduces ferredoxin providing reductant for nitrate and ritrite reduction and the conversion of glutamine to glutamate. ATF", in addition to driving the active transport mechanism of nitrate uptatie, is required by glutamire syrthetase to convert ammonium to glutamine. Irradiance j.s also required to insure that sufficient carbon steletons are available to accept ammonium in the formation of glutamine isyrett. 1981).

The energetic limitation of nitrate lptal:e was showr here to be brought about by the simultaneous reduction in iron and light availability (Figure 9). Ammorium uptat:e was also examined and was found to be largely independent of 
irradiance (Figure 2). Unlite nitrate, ammonium can enter the cell via normediated diffusion or by a cotransport mechanism driven by a charge gradient (Faven, 1980), and since it is completely reduced and availatle for conversion to glutamate, requires ittle reductant or ATF. These energetic considerations may account for the rapid uptal:e of ammonium in cultures incubated in total darkness.

Ammonium is preferred over nitrate as a nitragen source by freshwater and marine microalgae when available in adequate supply. Ammonium uptale and assimilation has been reported to be dependent on irradiance, however these reports are from studies conducted in the field with indigenous algae incubated in different light regimes (Friscu, 1994). I have examined the short-term uptalie of ammorium in cells that may have accumulated considerable reserves of carbotydrates prior to experimental incubation, which may for a limited time, provide reductant and ATF from respiration to drive ammonilum metabolism. As these cells were held in darliness these carbon reserves would diminish and it is litely that a reduction in ammorium uptake rates and a dependence on light intensity would emerge. Iron deficiency may decrease nitrogen metabolism because of energetic limitations or reductions in the synthesis or activity of enzymes involved in the metabolic pathway. Iron starvation has been reported to decrease 
nitrite reductase and glutamine synthetase activity in S트르르테늘 (Storch and Dunham, 1936). Accumulations of nitrite in the Fraquil medium of low-iron cultures might be expected because of these energetic and nutritional deficiencies. However the lact: of detectable nitrite and ammonium concentrations in all nitrate-grown cultures indicates that iron deficiency was not severe enough to bring about such responses. The rapid removal of ammonium from the Fraquil during the ammorium liptal:e experiments also suggests that the lowest iron concentration $10.01 \mathrm{H}$, 10-B M) used here did not hinder glutamine synthetase activity.

Chlarasis induced by nitragen deficiency is comman in plaris and has been demonstrated to reflect the ambient nitrogen concentration in the sea (Vaccaro and Fyther, 1960). Nitrogen as ammonium is incorporated into delta amino levulinic acid (ALA) during the synthesis of the heme portion of the chlorophyll malecule. Chlorophyll synthesis, however appears to be more sensitive to iron availability, which is required as ferredoxin to activate the synthesis of ALA, rather than nitrogen deficiency. Nitrogen appears to exert greater influence on chlorophyll synthesis in ironreplete cultures iron-deplete cultures (Figure 11 ).

The depression in chlorophyll a concentrations in iron-replete cultures $(1.0 \mathrm{HM})$ is similar to patterns 
occasionally seen in other physiological responses. Greater growth rates and more rapid depletion of nutrients in these iron-sufficient batch cultures may have produced this decline. A second possibility is that 1.0 ul iron concentrations provides excessive iron which may somehow interfere with normal metabolic processes.

Nitrogen sufficiency, as with iron and other nutrients is required for maximum photosynthetic efficiericy. Nitrogen deficiency influences fluorescence indices such as CFC more strongly than other nutrient deficiencies (vincert, 1980). Moderate reductions in nutrient availability may be ameliorated with an increase in irradiarice or other rutrients. This was seen when increased photon flux density decreased the reduction in photosynthetic carbor fixation in iron-deficient cultures as described in Chapter II and was also seen here with nitrogen deficiency.

Carbon and nitrogen uptake and assimilation pathways compete for metabolic energy (Ul1rich, 1983). This competition for reductant and ATF is intensified if photosynthetic capacity is reduced by nutrient deficiency or decreased irradiance. Ammonium, which requires less energy arid reductant than nitrate to be fully metabolized, permits greater carton fixation to occur at a given photon flux density. Short-term ammonium metabolism, as demonstrated. is largely independent of 1 ight. Ammonium is tat:en up by 
the cell very rapidly and ritrogen-deficient cells can quictily become nitrogen sufficient enhancing photosynthetic efficiency and decreasing the competition for photoreductant with the Calvin cycle permitting greater carbon fixation. Nitrate metabolism is more dependent on light because it consumes greater quantities of ATF and reductant than ammonium uptake and assimilation. A greater portion of chemical energy produced in photosynthesis is directed to the nitrate uptake arid assimilation pathway and this is reflected in decreased carbon fixation rates. This is also seen in the slope when photosynthetic carbon fixation is compared to irradiance in Figure 15: carbon assimilation increases more rapidly with irradiance for cultures incubated with ammorium thar nitrate.

\section{CONCLUSION}

Iron deficiency and reduced irradiance diminist

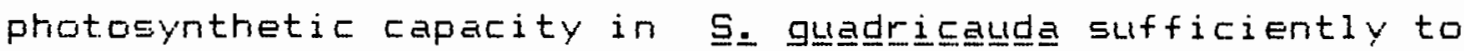
energetically limit nitrate uptatie rates. Moderate reductions in one parameter may be partially compensated for by an increase in the availability of the other. Ammonium depletion from the culture medium was found to be independent of irradiance and exceeded nitrate uptate in all iron concertrations and photon flux densities. Iron nutrition had ro effect on maximum ammonium uptake rates. 
Chlorophyll a concentrations and carbon fixation rates in nitragen-sufficient and ritrogen-deficient cultures were strongly influenced by the availability of iror. Oriy in iron-replete cultures do chloroptiyll a concentrations reflect nitragen deficiency. Likewise, high photon flux density is seen to compensate for nitrogen deficiency in carbon fixation rates. The competition for photochemical energy (ATF and reductant) between the nitrogen and carbon metabolism pathways is most pronounced in cultures using nitrate as a nitrogen source rather than ammonium. Ammonium, teing completely reduced, requires less reductant and ATF to be assimil ated by S. g느크모드느믈 ard supports greater rates of carbon fixation than completely oxidized nitrate. The nutrient and energetic interactions of iron: nitrogen, and photon flus density in regulating patterns of photosynthesis and carbon assimilation will be examined further in the following chapter. 
CHAFTEF $\quad$

FEEULATION OF FATTEFNS IN SHOFT -...TEFM

CAFEON METAEOLISM EY IFON NUTFITION

\section{INTFODUET ION}

Evaluation of photosynthetic carbon fixation rates with 14[ offers valuable insight into algal photosynthetic responses to changes in the physical or chemical environment. The relative synthesis of photosynthetic end products may be related to the nutritioral arid physiological status of an algal culture. These end product polymers may be grouped into 3 classes; 1) proteins, 2) polysaccharides, and 3) lipids and low molecular weight (LMW) metabolites. The latter group consists primarily of membranes and metabolic intermediates. The polysaccharide fraction includes structural cartahydrates such as cellulose, and starch, which functions as a fixed carbon pool. The protein comporient also includes the nucleic acids but these reportedly account for less than $5 \%$ of the total fraction (Morris et al., 1974).

Iron deficiency has been shown to increase rates of protein synthesis relative to other polymers in a marine dinoflagellate (Glover, 1977). This pattern is similar to 
photasynthate production in energetically-deficient, lightlimited culture of marine diatoms (Morris et al., 1974).

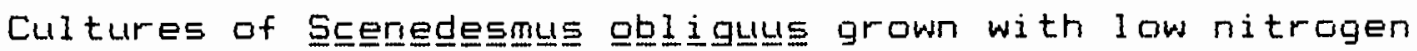
nutrition were found to have high (45\% of biomess) lipid concentrations (F'iorreck et al., 1994). Nitrogen deficiency was apparently severe enough to decrease protein synthesis; however it is important to note that these worlers were not looking at relative rates of polymer synthesis. In Chapter II it was shown that iron nutrition strongly influences the

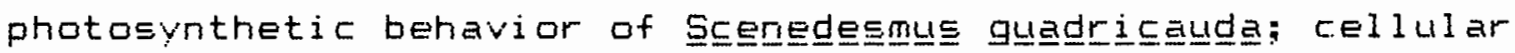
fluorescence capacity and carbon fixation rates are reduced in iron-deficient cultures. In Chapter IV it was shown that iron deficiency inhibited nitrate uptale rates. This chapter examines patterns of short-term carbon incorporation

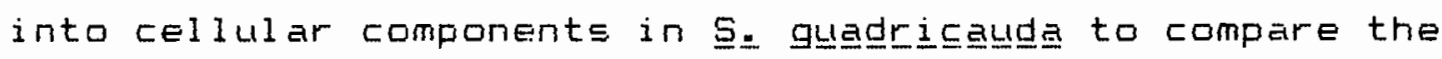
relative effects of iron and light on carbon and nitrogen metatolism. These patterns of incorporation were determined by the sequential extraction of the lipid-LMW metabolite, polysaccharide, and protein fractions.

METHODS

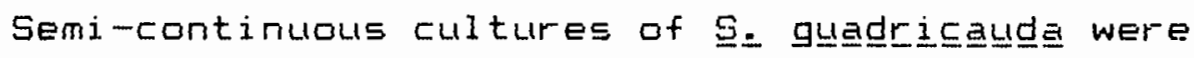
incubated 7 to 10 days in Fraquil medium (Morel et al., 1979; as modified by Fetersen, 1982). Iron concentrations of $1.0,0.5,0.1,0.05$, and $0.01 \mathrm{\mu M}(10-6$ to $10-8 \mathrm{M})$ were 
achieved with the addition of FeEDTA. Nitrate concentrations were either 200 MM for nitrate-replete cultures, or 10 MM for nitrate-deplete cultures. Light ard temperature were continuous at $100 \mu$ finsteins/m2/sec and $22^{\circ} \mathrm{C}$ respectively. Fatterns of inorganic carbon metabolism were examined using the method of Marris et al. (1974). Cultures were subdivided and spited with 50 m NaH14COS lactivity ca $5.0 \mathrm{\mu Ci} / \mathrm{ml}$ ) per $100 \mathrm{ml}$ of culture. These subcultures were wrapped with fiberglass screening and incubated at 27 , 53, and 170 jeinsteinsim2/sec for 2 hr. Temperature was held at 220C with a water bath. Darti bottles were wrapped in black: plastic.

Cultures were removed from the light field after incubation and 25 mi subsamples were vacuum-filtered onto GF/C glass fiber filters. Filters used for fractionation were placed in $\exists m l$ of $80 \%$ ethariol and frozen until extraction. Fieference filters were allowed to air dry ard placed in liquid scintillation vial for total 14C uptate Val LIES.

After extraction, $1 \mathrm{ml}$ of each ethanol and TCA fraction was added to $5 \mathrm{ml}$ of Solvent Free liquid scintillation coctitail and allowed to emulsify 12 to 24 tir. The filter with the protein fraction was placed directly in a LS vial. 14C uptatie was determiried using a Eectiman liquid scintillation counter. Each fraction was corrected for 
dilution and presented as a perrentage of total $14 \mathrm{C}$ incorporated in reference samples.

FESULTS

Fatterne of $14 \mathrm{C}$ incorporation indicate that a greater portion of the photoassimilated carbon is allocated to protein synthesis as iron deficiency becomes more pronounced (Figure 14). Frotein accounts for over $50 \%$ of the photosynthate in low iron cultures incubated at 5 S or 27 MEinsteins/mäsec. This fraction steadily declines as iron concentrations in the growth medium increase and more fixed carbon is incorporated inta the polysaccharide fraction. Syrthesis of the etharol-soluble lipid and LMW metabolite fraction remains largely unaffected by iron rutrition. No apparent pattern in photosynthate partitioning was observed in cultures incubated at. 170 MEinsteinsim2isec suggesting that high light may compensate for iron deficiency.

The partitionirig pattern seen in Figure 14 is similar to results reported for nitrogen-deficient or lightIimited cultures by Morris et al. (1974). To insure that iron nutrition rather than nitrogen nutrition was responsible for the results in Figure 14, experimemts were conducted with $200 \mathrm{LM}$ and $10 \mathrm{LM}$ ritrate concentratians in the culture medium. Although some variability in the results 


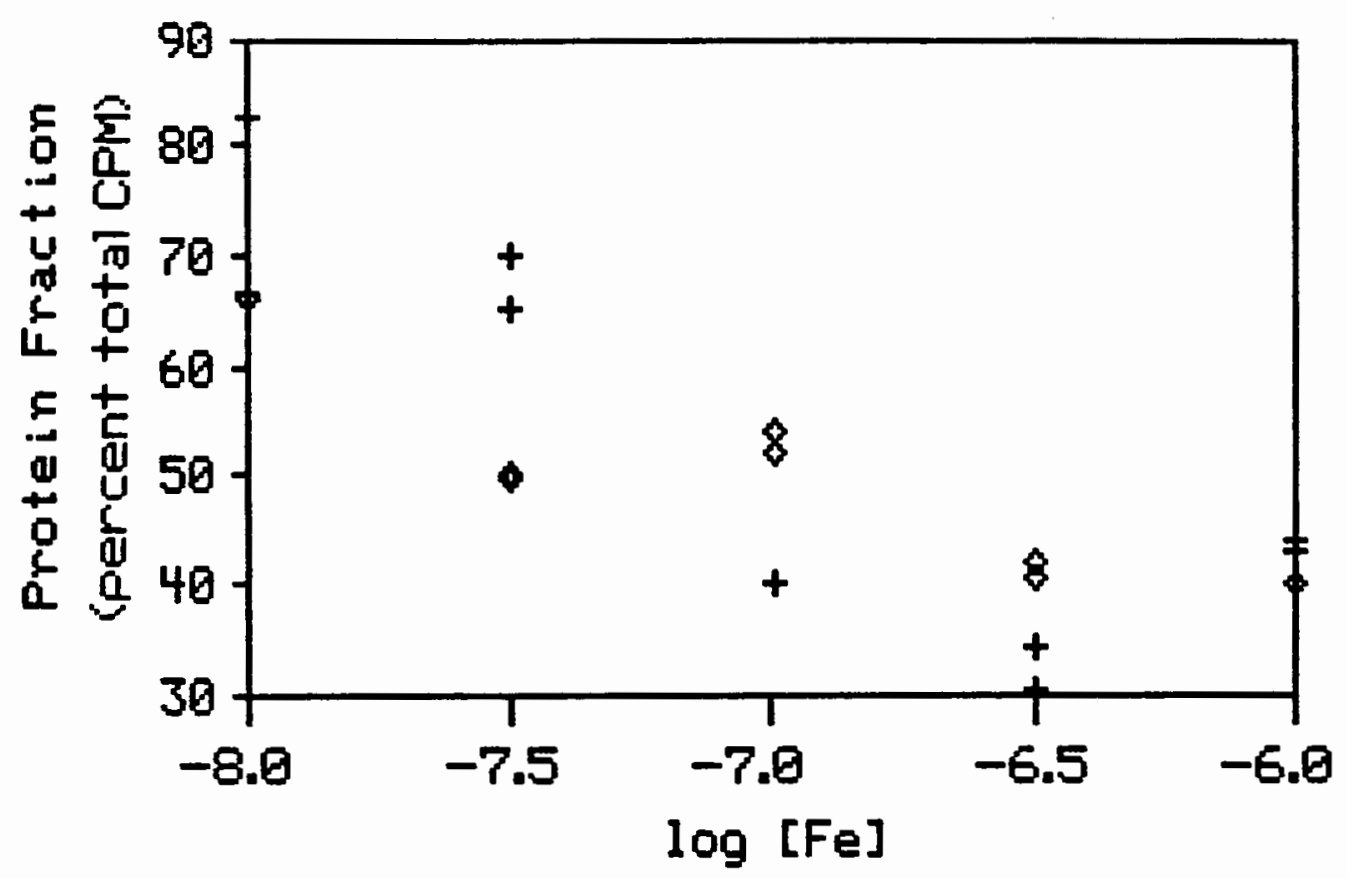

$+53 \mu \mathrm{Eins} / \mathrm{m} 2 / \mathrm{s} \diamond 27 \mu \mathrm{E} i n s / \mathrm{m} 2 / \mathrm{s}$

Eigure 14. Fatterns of 14C inicorporation irito cellular comporierits indicate that greater than $50 \%$ of the photoassimilated carbon is allocated to the protein component in iron-deficient cultures. This percentage decreases with increasing iron nutrition as more $14 \mathrm{C}$ is allocated to other cellular comporients. 
were obtained, patterns of protein synthesis were the same. Fielative rates of protein synthesis appears to be a physiological marler in iron-deficient cultures of $\underline{\underline{S}}$.

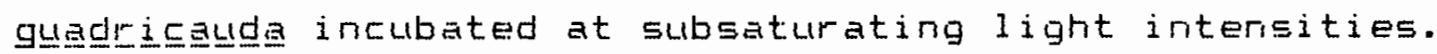
Glover (1977) reported similar trends in carbon metabolism in iron-starved cultures of marine algae. These cultures al $s 0$ demonstrated depressed carbon fixation rates ard assimilation efficiencies. Total protein synthesis, although declining with increasing iron deficiency, accounted for a greater percentage of the tatal $14 C$ incorporated.

Much of the assimilated carton is allocated to protein synthesis when photosynthetic rates are restricted by iron deficjency (Figure 15). Frotein accounts for much less of the total photosynthate in cultures with moderate to high carton fixation rates. Total protein syrthesis, however, is much higher in the iron-replete cultures than in the other cultures. For example in Figure 15, total protein production in the intermediate and high-iron cultures is approximately $75 \%$ greater than in the low-iron cultures but this difference is hidaen by the greater synthesis of other polymers in the iron-replete cultures.

\section{DISCUSSION}




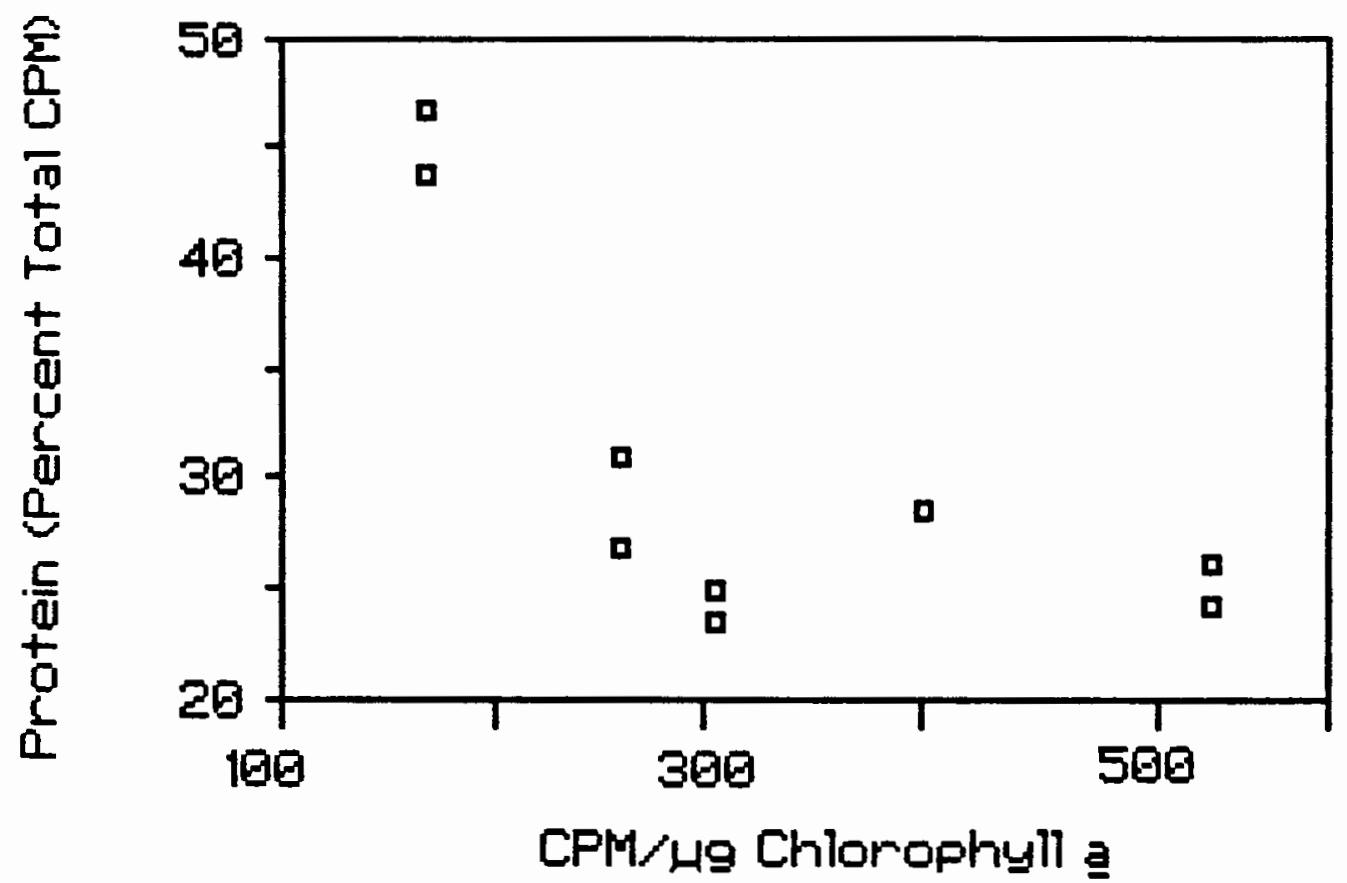

Eiqure 15. A comparison of photosynthetic rates and $14 \mathrm{C}$ incorporation into protein reveals that protein accounts for a relatively constant percentage of incorporated $14 \mathrm{C}$ in cultures with moderate to high iron nutrition. 
and is affected less in iron-deficient cultures. Iron deficiency, in addition to hindering photosynthetic efficiency and functioning as an energetic limitation to carbon fixation, may also increase protein turnover rates. Continued protein synthesis is essential if the metabolic machinery in the cell is to remain operational. The synthesis of the 1 ipid-LMW metabolite and polysaccharide fractions is also important to maintain cellular fitness, however the synthesis of these polymers is much more variable as they may also function as fixed-carbon reserves. The relative increase in polysaccharide synthesis in ironreplete cultures may indicate an increase in starch synthesis which might be anticipated if these cells can afford the energetic luxury of producing fixed-carbon reserves.

Similar patterns of carbon metabolism have been demonstrated in irori, light, and nitrogen-deficient cultures (Glover, 1977; and Morris et al., 1974, respectively). Iron and light deficiencies, as discussed in Chapter III, are both expressed as energetic limitations which decrease the rate of carbon fixation. Frotein synthesis may be enhanced by the release from nitrogen deficiency with the nitrate or ammonium addition that occurs prior to $14 \mathrm{C}$ incubation when nitrogen uptake rates are also examined. The sudden availability of nitrogen for amino acid synthesis could result in the rapid catabolism of other polymers to produce 
protein. However this respanse wauld reduce the amount of 14C incorporated into the new protein fraction since amino groups would be added to previously synthesized carbon st:eletons.

Frotein synthesis in cultures recertly released from nitrogen starvation is linked to nitrogen uptake (Syrett, 1981). In Chapter IV it was demonstrtated that nitrate uptat:e rates are greatest in iron-replete cultures. These cultures also have the greatest growth rates and total protein production. Froportional rates of protein synthesis, however were nat related to nitrate (or ammonium) uptake rates.

Carbon metabolism may be strongly affected by diurnal and temporal growth patterns. Morris et al., (1974) reported that polysaccharide and lipid-LMW metabolite synthesis was dependent on the stage of the algal 1 ife cycle whereas protein production was not. Fivitin (1985) showed that the ethanol-soluble fraction is catabolized for protein synthesis durirg the dart: phese of a diurnal cycle. These problems have been eliminated by incubating cultures urider contiruous light.

\section{CONCLUSION}

Frotein synthesis accourts for the largest fraction of the carbon fixed in iron-deficient cultures. Foly- 
saccharides replace frotein as the predominant polymer as iron concertrations in the culture medium increase. Total protein synthesis, however remains greater in iron-replete cultures which are photosynthesizing and growing mast rapidly. No clear pattern in carbon metabolism was seen in high-light cultures, possibly due to high light compensation for iron deficiencies. Nitrogen nutrition may also affect patterns of carbon metabolism: total protein synthesis was greatest in iron-replete cultures which, in other experiments also had greatest nitrate uptalie rates.

Conservation of protein synthesis reflects the metabolic priority of that fraction. Folysaccharides, Iipids and LMW metabolites are also critical for cell maintenarice but are much more variable. These fractions may al 50 serve as fixed-carbon pools which may be catabolized to produce protein. Greater polysaccharide synthesis in ironreplete cultures may also be attributed to greater growth rates and the increased demand for cellulose and fertias the synthesis of starch as a storage compound for extra fixedcarbon pools. The lipid-LMW fraction remains relatively unchanged by the iron nutrition of the culture. 
Chapter VI

\section{A GENERAL MODEL FOF IFION LIMITATION}

AND ENUIRONMENTAL SIGNIFICANCE

Iron nutrition strangly regulates photosynthetic

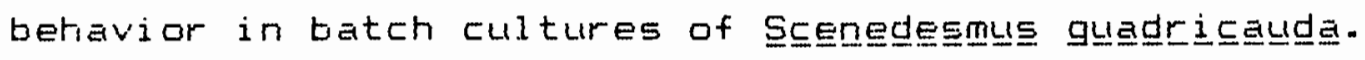
Carbon uptake per ug chlorophyl 1 a and total productivity is greatest in iron-replete cultures. Similar results have been reported in laboratory and field experiments with frestiwater and marine algae (Oquist, 1971; Miller et al., 1974; Glover, 1977; and Mueller, 1935). Cellular fluorescence capacity also reflects the iron nutrition of each culture, suggesting that iron deficiency may impede electron flow through the algal photosynthetic apparatus. This energetic hinderance is strongly linted to the otserved reductions in $14 \mathrm{C}$ photoassimilation and photosynthetic efficiency.

Iron deficiency decreases the chlorophyll a concentration in algae, possibly due to reductions in ferredoxin concentrations. Fluorescence indices, such as cellular fluorescence capacity, and chlorophyll a concentrations are good markers for possible iron deficiency in algal populations. These physiological marters were more sensitive to iron deficiency than growth or culture biomass 


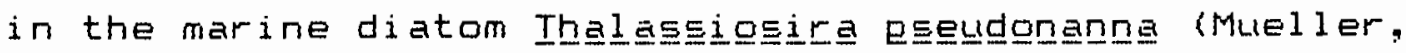
1985). Feductions in the primary light harvestirg pigment of the cell create energetic hinderances which are possibly exacerbated by decreased photosynthetic efficiencies.

Fluorescence indices have been linked to nutritionally influenced patterns of photosynthesis in natural populations of marine phytoplankton (Vincent, 1980). The demoristrated relationship between CFC and photosynthetic efficiency in

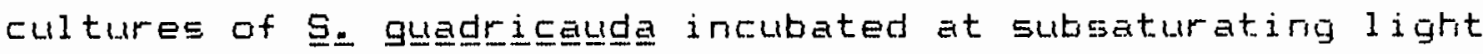
intensities may also occur in riatural populatiors. Further development and refinement of fluorescence indices may provide researchers with a valuable tool for investigating photosynthesis in natural phytoplankton populations.

Energetic limitations brought about by iron deficiency affect nitrogen metabolism as well as carton fixation. The uptalie, reduction, and assimilation of ritrate requires reductant and ATF, each a product of photosynthesis. Nitrate uptake and reduction accurs independently of nitrite reduction. Nitrate reduction to nitrite is less eriergetically demanding than the reduction of nitrite to ammorium. The occurrence of a deep-water nitrite maximum may be due to energetically limited nitrate metabolism in phytoplankton populations (kiefer et al., 1976). Fhytoplantiton growing in low-light environments might continue to take up and reduce nitrate to nitrite 
while rates of nitrite reduction decline, allowing nitrite to accumulate within the cell and eventually leak out into the surrounding environment. Nitrite production, which might be anticipated in the most energetically stressed cul tures (the 0.01 MM iron cultures incubated at 53 HEinsteins/maisec), was not observed, indicating that light and iron availability was adequate to support nitrite reduction to ammorium at rates which prevented the accumulation of nitrite in the culture medium.

Irorganic nitrogen and carbon uptal:e arid assimilation compete with other metabolic pathways for photochemical eriergy. Ammonium, a nitrogen source which requires less reductant and ATF than nitrate to be completely assimilated, is taken up more rapidly ard supports greater photosyrithetic activity than does a nitrate-nitrogen source. As expected, nitrate-replete cultures contairied more chlorophyll a and were more productive than nitrate-deplete cultures of $\leqq$. g느크토드느므. However productivity, independent of nitrate nutrition is strongly influenced by iron nutrition.

Chlorophyll a concentrations were greater in nitrate-replete cultures only if iron concentrations in the Fraquil were also high, thereby determining total productivity of the culture. Light also mitigates for nitrogen deficiency, reducing differences in photosynthetic rates among nitratesufficient and deficient cultures at higher intensities. 
The iron-nutritional status of experimental cultures is also reflected in patterns of carton metabolism in experimental cultures at subsaturating light intensities. Fatterns of $14 \mathrm{C}$ allocation into cellular components, as with patterns of nitrogen metabolism, are less defined when cultures are incubated at high light intensity. Fredictions of carbon allocation in energetically or nutritionallylimited cells can te made using a growth model developed by Shuter (1979). The Shuter model predicts that the synthesis of cellular components will be optimized in such a manner as to maintain maximum feasible growth rates under existing environmental conditions. Figure 16 illustrates the strategy of the shuter model.

Structural cell comporients in the Shuter madel are a fixed metabolic cost and must be maintained. Fieductions in carton assimilation due to energetic restrictions matilize carbon storage reserves which are catabolized to support structual and metabolic component synthesis. This preferential synthesis of certain cellular components is seen in iron deficient cultures which continue protein synthesis at the expense of the polysaccharide and 1 ipid-low molecular weight metabolite fractions. These other fractions also continue to be synthesized for the maintenance of structural and metabolic components, but protein synthesis accounts for an increasingly larger 


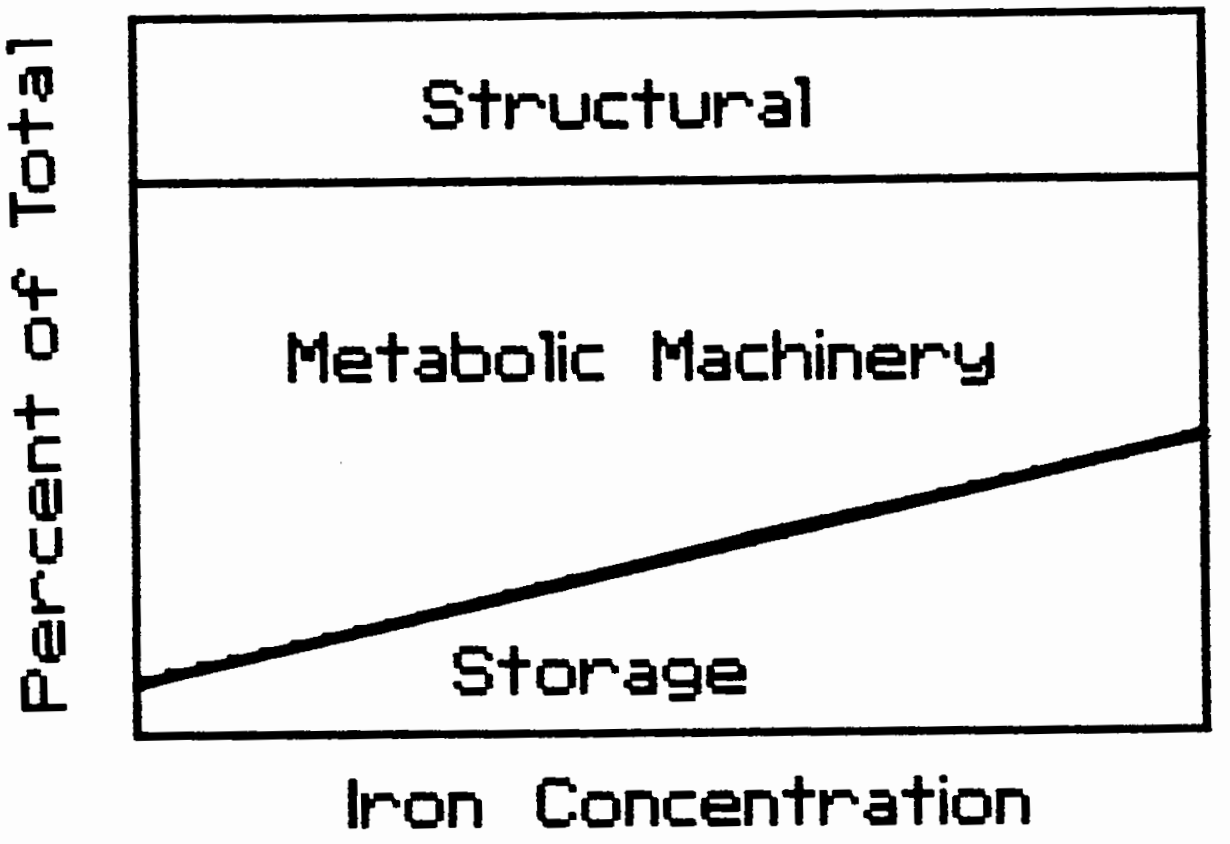

Eiguie 16. The effects of iron supply on cellular composition demonstrated with the Shuter model approach (Shuter, 1979). The relative width of each fraction indicates the percentage of total carbon allocated to each component. The Etructural component remains constant at all levels of nutrition. Metabolic machinery such as photosynthetic and respiratory proteins, account for an increasing amount of total cellular carbon as iron availability decreases at the expense of fixed-carbon reserves. 
portion of the total carbon assimilated as photosynthetic rates decline with increasing iron deficiercy.

Maintenance costs are proportional to culture growth rates and cell syrithesis. Cultures with moderate to high rates of carbon fixation allocate a relatively constant fraction of the fixed $14 \mathrm{C}$ to protein synthesis. This consistency was also seen in the lipid-LMW metabolite fraction at all iron concentrations. The proportional increase in the polysaccharide fraction from cell maintenance levels implies that iron-replete cultures are synthesizing starch as an energy storage pool in addition to the continued production of cellulose and other structural cartohydrates.

The goal of this research effort was to examine the physiological response of a common freshwater alga, $\underline{S}$ guaㅁ도도르믈 to changes in iron nutrition. Fiesponses to iron deficiency were often similar to responses in light-limiting conditions reported in the literature. Energetic restrictions are seen in carbon assimilation, nitrate metabolism, and photosynthate partitioning. Therefore, primary productivity in iron-limited natural waters would be partially restricted by greater inefficiencies in the algal photosynthetic apparatus, lower chlorophyll synthesis, and decreased nitrogen metabolism.

Iron limitation in a natural system will te less 
73

pronounced if easily assimilated nutrients are available for algal bise. Ammonium can support greater photosynthetic rates at lower light intensities and iron concentrations than nitrate-nourished cultures. Co-limitation of primary productivity is more likely to be observed than iron limitation alone. A system with low nitrogen and iron concentrations might be such an example; nitrogen would probably be identified as the limiting resource al though iron deficiency may energetically hinder the use of available nitrogen. 


\section{LITERATUFE CITED}

Anderson, M.A., and F.M. Morel. 1982. The influence of aqueous iron chemistry on the uptake of iron ty the

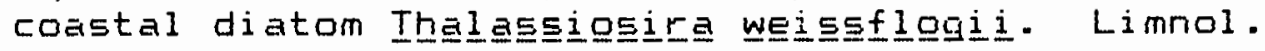
oceanogr. $27: 7 \overline{8} \overline{9}-\overline{8} \overline{1}$.

Eailey, K.M., and F.E. Taub. 1980. The effects of hydroxamate siderophores (strorig Fe (III) chelators) on the growth of algae. J. Fhycol. 16:354-359.

Erand, L.E., W.G. Sunda, and Fi.f.L. Guillard. 198.. Limitation of marine phytoplantton reproductive rates by zinc, manganese, and iron. Limnol. Gceariogr. 28: $1182-1199$.

Christenson, E.S. 198:. Effect of copper on cell division. nitrogen metabolism, morphology, and sexlal reproduction in the life cycle of closterium monilifferum (Chlorophyceae). Fh.D. thesis, Fortland State University, Fortlarid, Oregon, $150 \mathrm{pp}$.

Colliene, Fi.H. 1985. Fhatoreduction of iron in the epilimnion of acidic lates. Limnol. Oceanogr. 28:83100 .

Dorteh, Q., and H.L. Conway. 1984. Interactions between nitrate and ammonium uptake: variations with growth rate, nitrogen source, and species. Mar. Eiol. $79: 151-164$.

Glover, H.E. 1977. Effects of iron deficiency on Isochrysis

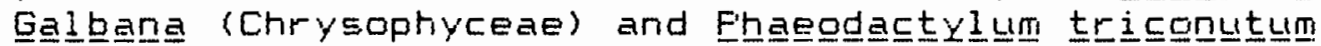
(Eaciliariophyceae). J. Fhycol. 1:208-212.

Glover, H.E. 1978. Iron in Maine coastal watersa seasonal variation and its apparent correlation with a diroflagellate bloom. Limnol. Deearogr. 23:534-537.

Goldman, C.R. 1972. The role of minor nutrients in 1 imiting the productivity of aquatic ecosystems. Limnol. Dceanogr. Spec. Symp. 1:21-35. 
Guikema, J.A. and L.A. Sherman. 1985. Organization and function of chlorophyll in membranes of cyanobacteria during iron starvation. Fiant Fhysiol. 73:250-256.

Huntsman, S. and W.G. Surida. 1980. The role of trace metals in regulating phytoplantton growth in I. Morris

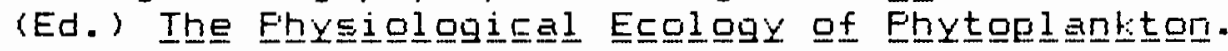
Univ. of Calif. Fress. Elerteley. pp. 235-s28.

Jones, M.N. 1984. Nitrate reduction by shaking with cadmium. Alternative to cadmium columns. Water Res. 18: $643-646$.

Kessler. E., and F. Czygar. 1967. The effect of iron supply on the activity of nitrate and nitrite reduction in green algae. Arch. Mikrobiol. 60:282284.

Kiefer, D.A., F.J. $0150 n$ and 0. Holm-Hansen. 1976. Arother look at the nitrite and chlorophyll maxima in the central North Facific. Deep Sea Fes. 23:1199-1203.

Lewin, Fi. 1984. How microorganisms transport iron. Science $225: 401-402$.

Miller, G.W., J.C. Fushnit, and G.W. Welkie. 1984. Iron chlorosis, a world wide problem, the relation of chlorophyll biosynthesis to iron. J. Flant Nutrition $7: 1-22$.

Miller, H.E., T.E. Maloney, and J.C. Greene. 1974. Algal productivity in 49 latie waters as determined by algal assays. Water Fies. 8:667-679.

Morel, F.M.M., J.G. Fiueter, Jr., D. M. Anderson, and F.F.L. Guillard. 1979. Aquil: A chemically defined phytoplankton culture medium for trace metal studies. J. Fhycol. 15:155-141.

Morris, I., H.E. Glover, and C.S. Yentch. 1974. Froducts of photosynthesis by marine phytoplankton: the effect of environmental factors on the relative rate of protein synthesis. Mar. Eial. 27:1-9.

Mueller, E. 1995. Some aspects of iron limitation in a marine diatom. Masters Thesis. Univ. of Eritish Col umbia. 104 pages. 
Murphy, T.F., D.F.S. Lean, and C. Nalewajbo. 1976. Eluegreen algae: their excretion of iron selective chelators enables them to dominate other algae. science 192: 900-902.

Qquist, G. 1971. Changes in pigment camposition and phatasynthesis induced by iron-deficiency in the blue-

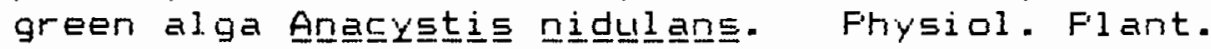
25: $188-191$.

Farsons, T.F., Y. Maita, and C.M. Lalli. 1984. E

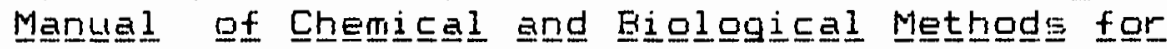

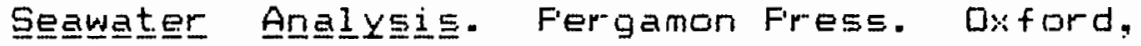
England. PP. 101-112.

Fetersen, Fi. 1992. Influence of copper and ainc on the growth of a freshwater alga, Scene르토는

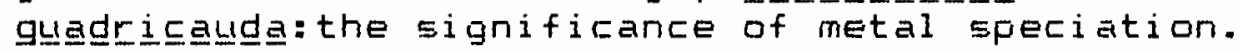
Eriv. Sci. \& Tecti. 16:445-447.

Fiorreck, M., K. Eaasch, and F. Fohl. 1984. Biomass production, total protein, chloroptiylls, lipids and fatty acids of freshwater green and blue-green algae under different nitrogen regimes. Fhytachem. 23:207216.

Frescott, G.W. 1979. How to know the Frestiwategr Alg Wm. C. Erown Co. Fublistiers. Duduque, Iowa. PP 52.

Frealin, B. 1981. Light reactions in photosynthesis. in

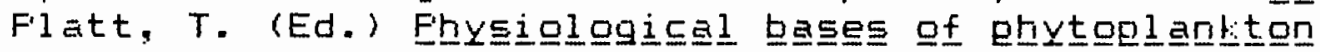
efoglggy Eul1. No. 210. Canadian Government Fublishing Centre. Hull, Quebec. pp. 1-4氵.

Frezlin, B.G. and A.C. Ley. 1980. Frotosynthesis arid chlorophyll a fluorescerice rhythms of marine phytoplaritori. Mar. Biol. 55:295-307.

Friscu, J.C. 1984. A comparison of nitrogen and carbon metabolism in the shallow and deep-water phytoplanliton population of a subalpine late. Fiesponses to photosynthetic photon flux density. J. Flankton fies. $6: 733-749$.

Faven, J.A. 1980. Nutrient transport in microalgae. Adv. Micrab. Fhysiol. 21:47-226. 
Fhee, G.Y., and I.J. Gotham. 1981. The effect of environmental factors on phytoplantton growth: Light and the interactions of light with nitrate limitation. Limnal. Dceanagr. 26:649-659.

Fivtin, F.E. 1985. Carbon-14 1 abelling patterns of individual marine phytoplankton from natural populations. Mar. Eiol. 89:135-142.

Samuelsson, G. and G. Oquist. 1977. A method for studying photosynthetic capacities of unicellular algae based on in $\underline{i} \underline{i} \underline{0}$ chloraphyll fluarescence. Fhysial. Flant. $40: 315-319$.

Sandmann, G. and F. Malkin. 1993. Iron-sulfur centers and activities of the photosynthetic electron transport chain in iron-deficient cultures of the bluegreen alga Aghangocapsa. Flant physiol. 73:724728.

Shuter, E. 1979. A model of physialogical adaptation in unicellular algae. J. Theor. Eicl. 78:519-522.

Smith, 5.V. 1984. Fhosphorus versus nitrogen limitation in the marine enviranment. Limnal. Dceanogr. 29: $1149-1160$.

Storch, T.A. and V.L. Dunham. 1936. Iron-mediated changes in the growth of Lat:e Erie phytoplankton and

axenic algal cultures. J. Ftrycol. 22:109-117.

Syrett, F.J. 1981. Nitrogen metabolism in microalgae in

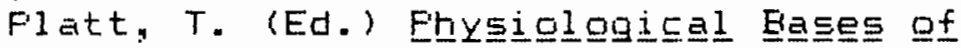
Ehytgel ankton Ecolggy. Eul1. No. 210. Canadian Government Fublishing Centre. Hull, Quebec. PP. $182-210$.

Terry, N. 1983. Limiting factors in photosynthesis. IV. Iron stress-mediated changes in light-harvesting and electron transport capacity and its effects on photosynthesis in vivo. Flant Fhysial. $71: 855-360$.

Trick, C.G., F.J. Andersen, A. Gillam, and F.J. Harrison. 198:. Frocentrin: an extracellular siderophore produced by the marine dinoflagellate Ergecentrum minimuri. Science 219:306-308. 
Ullrich, W.F. 1983. Uptake and reduction of nitrate: algae and furigi in Lauchli, A. and R.L. Ereleski

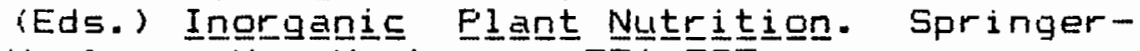

Verlag. New York. PP. $376-397$.

Vaccaro, F.F., and 3.H. Fyther. 1960. Marine phytoplankton and the distribution of nitrite in the sea. 3. Cons. Cons. Ferm. Int. Explor. Mer. 25:260-271.

Verstreate, D.Fi., T.A. Storch, and V.L. Dunham. 1980. A comparison of the influence of iron and nitrate

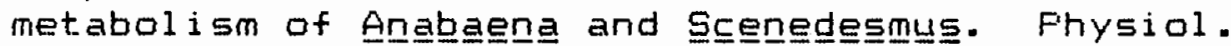
Flant. 50:47-51.

Vincent, W.F. 1980. Mechanisms of rapid photosynthetic adaptation in natural phytoplantiton communities. II. Changes in photochemical capacity as measured by DCMU-induced chlarophyll fluorescence. J. Fhycol. $16: 568-577$.

Wetzel, R.G. 1975. Limnglogx. W. H. Saunders Co. Fhiladelphia. PP. 246-261.

Wetzel, R.G. and G.E. Likens. 1979. Limnologicaㅢ Angalysis W. E. Saunders Company. Fhiladelphia. pp.83-84.

Zunft, W.G. and H. Spiller. 1971. Characterization of a flavodoxin from the green alga Chlogelella. Biachem. and Eiophysical Fiesearch Comm. 45:112-116. 